\title{
EL RECURSO PREVIO DE INCONSTITUCIONALIDAD SEGÚN LA LEY ORGÁNICA 12/2015: UN REGRESO ESPERADO, UNA REFORMA INSUFICIENTE
}

MIGUEL ÁNGEL ALEGRE MARTÍNEZ 
SUMARIO

INTRODUCCIÓN. I. EL RECURSO PREVIO DE INCONSTITUCIONALIDAD HASTA SU SUPRESIÓN EN 1985. II. EL DEBATE SOBRE LA NECESIDAD DE SU RECUPERACIÓN. III. ANTECEDENTES INMEDIATOS: LAS PROPOSICIONES DE LEY ORGÁNICA DE 24 DE ENERO DE 2014. IV. LA LEY ORGÁNICA 12/2015: TRAMITACIÓN, JUSTIFICACIÓN Y CONTENIDO. V. LA LEY ORGÁNICA 12/2015: ANÁLISIS, VALORACIÓN Y PROPUESTAS. CONCLUSIONES. BIBLIOGRAFÍA. 


\title{
EL RECURSO PREVIO DE INCONSTITUCIONALIDAD SEGÚN LA LEY ORGÁNICA I 2/2015: UN REGRESO ESPERADO, UNA REFORMA INSUFICIENTE
}

\author{
MIGUEL ÁNGEL ALEGRE MARTÍNEZ ${ }^{1}$
}

Profesor Titular de Derecho Constitucional. Universidad de León (España)

\section{IINTRODUCCIÓN}

La Ley Orgánica 12/2015 de 22 de septiembre (BOE de 23 septiembre 2015) ha traído de vuelta a nuestro ordenamiento jurídico la figura del recurso previo de inconstitucionalidad (RPI) para — según reza su enunciado— «los Proyectos de Ley Orgánica de Estatuto de Autonomía o de su modificación».

Se recupera así parcialmente un procedimiento ante el Tribunal Constitucional, previsto originalmente en el artículo 79 de la Ley Orgánica 2/1979 de 3 de octubre (LOTC) tanto para Estatutos de Autonomía como para Leyes Orgánicas, ampliamente denostado en su momento (hasta que se logró su supresión en 1985), y posteriormente objeto de atención por parte de la doctrina española, sobre todo en el contexto de la serie de reformas de Estatutos de Autonomía llevadas a cabo a partir de 2006. Las circunstancias que rodearon a esa dinámica reformadora generaron la sensación de que no todo estaba dicho en torno al recurso previo. Curiosamente, y a pesar de ese renovado interés, la Ley Orgánica que reintroduce el RPI ha pasado en cierto modo desapercibida: en

${ }^{1}$ Miguel Ángel Alegre Martínez, Departamento de Derecho Público, Universidad de León. Facultad de Derecho. Campus de Vegazana, s/n. 24071 LEÓN Email: maalem@unileon.es 
parte, porque la conocida como última oleada de reformas estatutarias ya había sido fiscalizada por el Tribunal Constitucional a través del recurso de inconstitucionalidad a posteriori (SSTC 247/2007 de 12 de diciembre, 249/2007 de 13 de diciembre, $31 / 2010$ de 28 de junio, 30/2011 de 16 de marzo); y en parte, porque otra reforma de la LOTC (la llevada a cabo por la Ley Orgánica 15/2015 de 16 de octubre, relativa a la ejecución de las resoluciones del Tribunal Constitucional como garantía del Estado de Derecho, avalada por el propio Tribunal el 3 de noviembre de 2016) ha coincidido prácticamente en el tiempo con la que nos ocupa, acaparando mayor atención mediática y doctrinal ${ }^{2}$.

Así las cosas, creemos que puede resultar ilustrativa una recapitulación, siquiera esquemática, sobre la experiencia del control previo de constitucionalidad en nuestro país, y en concreto la inclusión del mismo en el artículo 79 de la misma LOTC para controlar con carácter preventivo los Estatutos de Autonomía y las demás leyes orgánicas, así como la supresión de este precepto en 1985, el posterior resurgimiento del debate, y los pasos que han conducido a esa recuperación parcial del RPI (especialmente las dos proposiciones de Ley Orgánica registradas con este fin en el Congreso de los Diputados el 24 de enero de 2014). Todo ello ha de proporcionarnos los elementos suficientes para analizar el contenido y valorar el significado de la LO 12/2015, sobre todo desde el punto de vista de su idoneidad —o falta de ella — para el control de eventuales reformas estatutarias futuras, teniendo siempre en cuenta que el control de constitucionalidad (independientemente de su carácter previo o sucesivo) ha de ser garantía y no obstáculo para que el Tribunal Constitucional pueda cumplir satisfactoriamente la función de defensa constitucional que tiene encomendada ${ }^{3}$.

${ }^{2}$ Véase, por ejemplo, E. GonZÁLEz HernÁNDEZ, «El artículo 155 CE y la LO 15/2015, de 17 de octubre, de reforma de la LOTC: ¿Ineludible reciprocidad o círculo perverso?», Teoría y Realidad Constitucional, n. ${ }^{\circ}$ 37, 2016, especialmente en págs. 230-232.

3 Tal y como indica S. Muñoz Machado (Informe sobre España, Barcelona, Ed. Crítica, 2012, págs. 207 y ss.), «Depende de la justicia constitucional que la Constitución misma sea preservada. Si las leyes que la vulneran no son inmediatamente anuladas y dejadas de aplicar, si las actuaciones de los poderes públicos que invaden competencias que no les pertenecen no son corregidas, la Constitución misma queda desplazada y su imperio sustituido por el de los legisladores ordinarios». Mantiene este autor la tesis de que «el modelo de justicia constitucional concentrada ha reducido la garantía de los derechos de los ciudadanos y está siendo incapaz de preservar la integridad de la Constitución». A ello contribuye, entre otros factores, y por lo que aquí más nos atañe, una de las dificultades a las que se enfrentan las sentencias de inconstitucionalidad: «que habrán tardado años en producirse, durante los cuales se habrá seguido aplicando la ley inconstitucional y no la Constitución. Este aplazamiento y sus consecuencias alcanzan la máxima gravedad cuando la disposición impugnada es, a su vez, norma habilitante de otras normas, como ocurre con los Estatutos de Autonomía, de modo que mientras se resuelve la impugnación no sólo seguirá vigente una ley contraria a la Constitución, sino que se habrán dictado, con apoyo en ella, otras 


\section{EL RECURSO PREVIO DE INCONSTITUCIONALIDAD HASTA SU SUPRESIÓN EN 1985}

El primer paso para contextualizar la recuperación del RPI en 2015, nos lleva a establecer la inevitable conexión con su antecedente: el desaparecido recurso previo de inconstitucionalidad que el artículo 79 LOTC establecía «contra proyectos de Estatutos de Autonomía y de Leyes Orgánicas» ${ }^{4}$. Dicho precepto, derogado en virtud de la Ley Orgánica 4/1985 de 7 de junio, establecía lo siguiente:

«1. Son susceptibles de recurso de inconstitucionalidad, con carácter previo, los proyectos de Estatutos de Autonomía y de Leyes orgánicas. El recurso tendrá por objeto la impugnación de:

que adolecen de idéntico vicio original. Puede hacerse una evaluación del problema que describo considerando que el recurso de inconstitucionalidad interpuesto contra el Estatuto de Cataluña en 2006 fue resuelto a mediados de 2010. Durante esos años el legislador catalán produjo muchas normas en desarrollo de preceptos estatutarios».

En efecto, la declaración de inconstitucionalidad de algunos preceptos de la reforma del Estatuto catalán por parte de la STC 31/2010, de 28 de junio, planteó problemas de seguridad jurídica en relación con numerosas leyes de desarrollo del Estatuto anteriores a la Sentencia (por ejemplo, Leyes 2/2009, de 12 de febrero, y 17/2009, de 16 de octubre, del Consejo de Garantías Estatutarias; Ley 12/2009, de 10 de julio, de Educación; Ley 24/2009, de 23 de diciembre, del Sindic de Greuges, Ley 4/2010, de 17 de marzo, de consultas populares por vía de referéndum, etc.). Más recientemente, la STC 128/2016, de 7 de julio, declara inconstitucionales varias disposiciones de la Ley catalana de medidas fiscales, financieras y administrativas por invadir competencias del Estado. En concreto, se declaran inconstitucionales dos artículos y varias disposiciones adicionales de esta ley (Ley de Cataluña 3/2015, de 11 de marzo), en las que el Parlamento catalán dirige al Gobierno de la Generalitat diversos mandatos que inciden en ámbitos como la administración tributaria, la presentación de un plan director relativo a los sectores de la energía, las telecomunicaciones, los sistemas de información y del transporte ferroviario, así como la creación de un Servicio Meteorológico de Cataluña. En cuanto a la creación de una Agencia Catalana de Protección Social y a la elaboración de un inventario del patrimonio de las Administraciones públicas de Cataluña, se establece una interpretación conforme con la Constitución de las respectivas disposiciones adicionales.

${ }^{4} \mathrm{Al}$ respecto, entre otros: F. SANTAOlalla LóPEZ, «Problemas del recurso previo de inconstitucionalidad y adición sobre la LOAPA», Revista de Derecho Político, n. ${ }^{\circ} 18-19,1983$, págs. 177190; M. GERPE LANDíN, «El control previo de constitucionalidad», Revista Jurídica de Cataluña, n. ${ }^{\circ}$ 1, 1983, págs. 197-207; J. PÉREZ ROYO, «Crónica de un error: el recurso previo de inconstitucionalidad contra leyes orgánicas», Revista Española de Derecho Constitucional, n. ${ }^{\circ} 17,1986$, págs. 137 170; A. J. Gómez Montoro, «El control previo de constitucionalidad de proyectos de Estatutos de Autonomía y demás Leyes Orgánicas», Revista Española de Derecho Constitucional, n. ${ }^{\circ} 22,1988$, págs. 121-174; A. SÁnchez De Vega García, «Acerca del recurso previo de inconstitucionalidad», Revista de las Cortes Generales, n. ${ }^{\circ} 23,1991$, págs. 53-77; M. A. Alegre MarTíneZ, Justicia constitucional y control preventivo, Secretariado de Publicaciones de la Universidad de León, 1995. 
a) El texto definitivo del proyecto de Estatuto que haya de ser sometido a referéndum en el territorio de la respectiva Comunidad autónoma en el supuesto previsto por el artículo $151,2,3 .^{\circ}$ de la Constitución. En los demás casos se entenderá que es texto definitivo del Estatuto de Autonomía el que, con arreglo al apartado siguiente, se establece para los demás proyectos de Leyes orgánicas.

b) El texto definitivo del proyecto de Ley orgánica tras su tramitación en ambas Cámaras y una vez que el Congreso se haya pronunciado, en su caso, sobre las enmiendas propuestas por el Senado.

2. Están legitimados para entablar el recurso previo de inconstitucionalidad quienes, de acuerdo con esta Ley, están legitimados para interponer el recurso de inconstitucionalidad contra Estatutos de Autonomía y Leyes orgánicas del Estado. El plazo para la interposición del recurso será el de tres días desde que el texto definitivo del proyecto recurrible estuviere concluido. La interposición del recurso suspenderá automáticamente la tramitación del proyecto y el transcurso de los plazos.

3. El recurso se sustanciará en la forma prevista en el capítulo II del título II de esta Ley.

4. a) Cuando el pronunciamiento del Tribunal declare la inexistencia de la inconstitucionalidad alegada, seguirá su curso el correspondiente procedimiento.

b) Si, por el contrario, declara la inconstitucionalidad del texto impugnado, deberá concretar ésta y el precepto o preceptos constitucionales infringidos. En este supuesto, la tramitación no podrá proseguir sin que tales preceptos hayan sido suprimidos o modificados por el órgano competente.

5. El pronunciamiento en el recurso previo no prejuzga la decisión del Tribunal en los recursos que pudieren interponerse tras la entrada en vigor con fuerza de Ley del texto impugnado en la vía previa».

El estudio de la supresión del RPI, centrado en los debates conducentes a la elaboración de la Ley orgánica 4/1985 de 7 de julio y en la STC 66/1985 de 23 de mayo, permite afirmar, por una parte, el carácter jurisdiccional del RPI (fundamento jurídico 2 de la citada sentencia); y por otra, que, si bien el Tribunal se pronunció a favor de la constitucionalidad de la supresión del recurso previo, no afirmó la inconstitucionalidad del mismo. Por el contrario, se refirió, si bien de forma marginal, a su carácter praeterconstitucional, pero no inconstitucional, en el sentido de que el RPI amplía «no contra la Constitución, pero sí al margen de ella, el ámbito del recurso de inconstitucionalidad que ésta [arts. 161.1.a) y 162.1.a)] instauró» (FJ 2). Igualmente, el Tribunal declaró que el contenido de la LOTC es disponible para el legislador, de tal manera que el RPI, introducido por una Ley orgánica, podía ser suprimido por otra; a lo que puede añadirse que, dado que no se declara la inconstitucionalidad de esta 
figura, no existirían, al menos desde este punto de vista, obstáculos para su recuperación 5 .

Resulta revelador al respecto el testimonio del entonces presidente del Tribunal Constitucional, Manuel García Pelayo que, a punto de cesar en su cargo, y entrevistado por un medio de comunicación, declaraba: «Cuando el Tribunal abordó el recurso contra la ley que suprimía el recurso previo, sólo podía tratar el tema en términos jurídicos. Lo que no está en la Constitución, sino en una ley orgánica, puede ser modificado por otra ley orgánica. Por consiguiente, el tribunal, por unanimidad, declaró dicha reforma como constitucional. Otra cosa es si hubiera sido prudente mantener el recurso previo. No le niego que yo así lo creía y lo creo, pero por la razón antedicha no puse, ni puedo poner, ninguna objeción a la constitucionalidad de su supresión ${ }^{6}$.

Como es sabido, el control previo de constitucionalidad sí se ha mantenido ininterrumpidamente en el ordenamiento español respecto de los tratados internacionales, merced al mecanismo previsto en el artículo 95 de la Constitución y desarrollado en el artículo 78 LOTC. A diferencia del RPI, esta modalidad ha generado cierto consenso doctrinal en cuanto a su justificación, a la vista del carácter internacional de las normas objeto de control, y los especiales inconvenientes que acarrearía su declaración de inconstitucionalidad a posteriori ${ }^{7}$.

5 En tal sentido, M. A. Alegre Martínez, «Sobre la conveniencia de recuperar el recurso previo de inconstitucionalidad», en P. PÉrez Tremps (Coord.), La reforma del Tribunal Constitucional. Actas del V Congreso de la Asociación de Constitucionalistas de España, Valencia, Tirant lo Blanch, 2007, págs. 243-270. Por su parte, A. J. Gómez Montoro apunta que «el hecho de que en la Constitución no se recogiera este tipo de control no suponía automáticamente su inconstitucionalidad, ya que la misma Constitución dejaba abierta una puerta para que mediante ley orgánica se introdujeran nuevas competencias del Tribunal Constitucional». Ahora bien, el hecho de que el recurso previo apareciera dentro de la LOTC en un título aparte, hace que parezca «como si los propios legisladores de la LOTC hubiesen sido conscientes de que se trataba de algo anómalo, que no encajaba en el sistema previsto en la Constitución» («El control previo de constitucionalidad de proyectos de Estatutos de Autonomía y demás leyes orgánicas», cit., pág. 141).

${ }^{6}$ Entrevistado por B. De la Cuadra, en El País, 19 de febrero de 1986. La cursiva es nuestra.

7 Incluso algún autor va más allá, al demostrar que el control a posteriori de los tratados internacionales es una «opción excluida por el constituyente español». Así, L. Jimena QuESADA, «La inconstitucionalidad del control de constitucionalidad sucesivo de los tratados internacionales (crítica a la postura mantenida por el Tribunal Constitucional español)», en P. PÉRez Tremps (Coord.), La reforma del Tribunal Constitucional. Actas del V Congreso de la Asociación de Constitucionalistas de España, Valencia, Tirant lo Blanch, 2007, págs. 419-439. El mismo autor desarrolla esta línea argumental en su trabajo «El lugar de la Constitución en los instrumentos internacionales sobre derechos humanos», en Rumbos del Derecho Internacional de los Derechos Humanos. Estudios en Homenaje al Profesor Antônio Augusto Cançado Trindade, Tomo V, Brasil, Porto Alegre, Sergio Antonio Fabris Editor, 2005, págs. 195-256, especialmente en págs. 237-238. 
Baste aquí con recordar que, a través de esta vía, el Tribunal dictó, en primer lugar, la Declaración de 1 de julio de 1992, respondiendo al requerimiento formulado por el Gobierno de la Nación sobre la necesidad o no de modificar la Constitución española como paso previo a la ratificación del Tratado de la Unión Europea firmado en Maastricht el 7 de febrero de 1992. El Tribunal apreció la existencia de contradicción respecto del artículo 13.2 CE, estableciendo que para obtener la adecuación al Tratado, era necesario proceder a la reforma de dicho precepto constitucional por la vía del artículo 167. Pero además, y por lo que aquí interesa, dicha Declaración permite afirmar, con el propio Tribunal, el carácter jurisdiccional de esta modalidad de control, así como la plena equiparabilidad de esta resolución a las sentencias. El control previo de tratados queda, además, configurado como un procedimiento encaminado a garantizar la supremacía constitucional, garantizando al mismo tiempo la seguridad y estabilidad de los compromisos internacionales ${ }^{8}$.

El mecanismo del control previo de tratados se ha utilizado, en segundo lugar, en relación con el Tratado por el que se establece una Constitución para Euro$p a$, firmado en Roma el 29 de octubre de 2004. La ratificación del Tratado Constitucional por parte de España no pasaba únicamente por la respuesta ciudadana en el referéndum de 20 de febrero de 2005 (76,73\% de votos afirmativos, con una participación del 43,32\%). Como se encargó de recordar el Consejo de Estado en su dictamen de 21 de octubre de 2004, se requería también la autorización de las Cortes mediante ley orgánica en virtud del artículo 93 CE (lo cual se materializó en la LO 1/2005 de 20 de mayo). Además, el Consejo de Estado dictaminó «que, con carácter previo a la ratificación, es conveniente que se haga uso de la facultad prevista en el artículo 95.2 de la

${ }^{8}$ Véase I. Villaverde Menéndez, «El control previo de constitucionalidad de las normas con rango de ley. Crónica de un escéptico», Revista Catalana de Dret Public, n. ${ }^{\circ} 49,2014$, págs. 20-40, en concreto págs. 35-36.

Una visión comparativa del control de constitucionalidad de los tratados y de la problemática de su ejercicio a priori o a posteriori, con referencia específica al interés que el tema suscita en México, puede verse en J. Brage Camazano, La acción abstracta de inconstitucionalidad, México, Universidad Nacional Autónoma de México, Instituto de Investigaciones Jurídicas (Serie «Doctrina

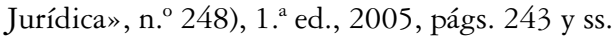

Por su parte, N. García GeStoso ha considerado que «pudiera ser adecuada [...] la flexibilización de los requisitos exigidos para suscitar un control preventivo de la constitucionalidad de las futuras reformas de los Tratados constitutivos, o incluso su transformación en un control preceptivo de alcance general» («Algunas consideraciones sobre las reformas de la Constitución española de 1978 derivadas de la integración europea», en Seminario de Profesores de Derecho Constitucional: La reforma constitucional, Universidad de Castilla-La Mancha, 18 de junio 2004, www.uclm.es/actividades0304/seminarios/reforma_constitucional/ponencias/noemi.pdf, pág. 24. 
Constitución para que el Tribunal Constitucional declare si existe o no contradicción» entre el Tratado Constitucional y la Constitución española. De acuerdo con ello, y pese a sus reticencias iniciales, el Gobierno, tras el Consejo de Ministros de 5 de noviembre de 2004, elevó al Tribunal Constitucional el requerimiento al que hace referencia dicho precepto constitucional. De esta manera se dio (aunque parcialmente) satisfacción a la necesidad, generalmente sentida, de que los ciudadanos pudieran acudir al referéndum de 20 de febrero de 2005 conociendo la resolución dictada por el Alto Tribunal en respuesta a dicho requerimiento, esto es, la Declaración 1/2004 de 13 de diciembre. De todas formas, como acabamos de adelantar, esta Declaración no sirvió para despejar totalmente las dudas sobre la adecuación entre Constitución y Tratado. Y ello, no solo por la existencia de tres votos particulares discrepantes respecto de la conclusión a la que llegan la mayoría de Magistrados constitucionales (la cual puede resumirse en la no existencia de contradicción entre la Constitución y los preceptos del Tratado que fueron objeto de requerimiento, así como en la suficiencia del artículo 93 para la prestación del consentimiento del Estado sin necesidad de reforma constitucional); sino, sobre todo, por el hecho que, tanto del requerimiento del Gobierno como de los términos del fallo de la Declaración, y merced al principio de congruencia, se infiere que la ausencia de contradicción solo queda afirmada respecto de los preceptos concretos de éste que fueron mencionados en las dos primeras preguntas formuladas por el Gobierno. La adecuación no era, por tanto, incontestable respecto de los demás contenidos del Tratado, respecto de los cuales, por una u otra razón, no fue preguntado el Tribunal, ni por el Gobierno, ni por «cualquiera de las Cámaras» (también legitimadas para emprender este procedimiento según el artículo 95.2 de la Constitución). El alcance del control queda, pues, a merced del contenido del requerimiento?.

9 Recordemos, a propósito de la secuenciación temporal entre control de constitucionalidad y referéndum, que la Declaración del Tribunal Constitucional 1/2004, de 13 de diciembre, en relación con la llamada Constitución europea, se produjo antes del referéndum de 20 de febrero de 2005; y ciertamente no faltó quien utilizó el hecho de que el Tribunal no hallara contradicciones entre el Tratado y la Constitución respecto de las preguntas formuladas, como argumento a favor del sí en dicho referéndum. En todo caso, la doctrina se encargó en aquel momento de recordar la conveniencia de que los ciudadanos acudieran a votar una vez conocida la resolución del Tribunal. En este sentido, por ejemplo, P. GonZÁlez-Trevijano, «Colisión entre constituciones», Diario ABC, 6 de noviembre de 2004, para quien el requerimiento al Tribunal «debería ser, aunque no es preceptivo, previo al reseñado referéndum. Conoceríamos con antelación la constitucionalidad de lo que votamos, evitaríamos el peligro de una posterior declaración de inconstitucionalidad, con su correlativo efecto de ineficacia interna, y escaparíamos a posibles responsabilidades internacionales. Al Tribunal Constitucional compete pues su resolución (artículo 78 LOTC), y al Gobierno (artículo 95.2 
La comparación entre los distintos modelos de control previo y sucesivo, así como el análisis de sus semejanzas y diferencias, nos lleva a percibir que la diferencia esencial que justifica esta clasificación dicotómica se balla en relación con el becho de que el texto sometido a control haya entrado o no en vigor, con el consiguiente reflejo en la manera de producirse la depuración objetiva del Ordenamiento. El control previo logrará una depuración a priori, evitando que llegue a estar vigente, y por tanto a ser obligatoria y aplicable, una ley contraria a la Constitución. El control sucesivo cumplirá su función mediante la eliminación del Ordenamiento de una norma jurídica hasta entonces vigente ${ }^{10}$.

CE) — también a las Cámaras (artículos 157 y 147 de los Reglamentos del Congreso y del Senado)_ obrar según los mandatos constitucionales».

Si la resolución del Tribunal hubiera afirmado la existencia de contradicción entre la Constitución y el Tratado (al menos en alguno de los puntos objeto de requerimiento), no habría procedido la celebración del referéndum, y el camino a seguir habría sido el indicado por el artículo 95.1 CE. Si, como fue el caso, el Tribunal no apreciaba inconstitucionalidad y el referéndum se celebraba, ello no tendría por qué condicionar necesariamente a los electores a la hora de votar a favor o en contra del tratado.

${ }^{10}$ Compartimos en este aspecto la posición de I. Villaverde Menéndez, quien niega rotundamente que el control previo de constitucionalidad mute la naturaleza de la función que ejerce el Tribunal Constitucional: «Ejercer la jurisdicción constitucional mediante controles previos no hace de la función ejercida por el TC una función consultiva y no jurisdiccional». La razón no está tanto en que el órgano sea un tribunal, como en el hecho de que, también cuando es llamado a resolver preventivamente sobre la constitucionalidad de una norma, sus decisiones son irrevocables: «La única diferencia, y no menor, con el control sucesivo está en el momento en el que se produce» («El control previo de constitucionalidad de las normas con rango de ley. Crónica de un escéptico», cit., págs. 35-36).

A la clasificación control previo - control sucesivo se refiere L. Pegoraro, poniéndola en relación con la que distingue entre control abstracto y control concreto: «En particular la [propuesta] que incide en la distinción entre control previo y control sucesivo evidencia el factor representado por la 'fase' del control, a diferencia de las que insisten en la mayor o menor conexión con un contencioso concreto. En particular, se observa que mientras el control preventivo es siempre abstracto, no es cierto lo contrario, que el control abstracto sea siempre preventivo» («Clasificaciones y modelos de justicia constitucional en la dinámica de los ordenamientos», en J. Pérez Royo, J. P. Urías Martínez y M. Carrasco Durán (Eds.), Derecho Constitucional para el Siglo XXI, Actas del VIII Congreso Iberoamericano de Derecho Constitucional, Navarra, Thomson/Aranzadi, 2006, Tomo II, págs. 4201-4225, en concreto págs. 4210-4211.

Véase también F. Fernández SEgADO, «La obsolescencia de la bipolaridad 'modelo americano/modelo europeo-kelseniano' como criterio analítico del control de constitucionalidad y la búsqueda de una nueva tipología explicativa», Parlamento y Constitución. Anuario, Cortes de Castilla-La Mancha, Universidad de Castilla-La Mancha, n. ${ }^{\circ}$ 6, 2002, págs. 9-73. Este autor sitúa la dicotomía control previo / control sucesivo como una clasificación relativa al control de constitucionalidad de la ley, en la que el criterio determinante es «el momento de verificación del control», 
La consideración de ambas modalidades de control, a través de los distintos planteamientos doctrinales, las tendencias observables y la práctica jurisprudencial en diversos ordenamientos de nuestro entorno en los que el control previo se ha venido ejerciendo de uno u otro modo (Francia, Italia, Portugal y España) permite delimitarlo conceptualmente caracterizándolo como aquella modalidad de control jurisdiccional concentrado de constitucionalidad, que tiene carácter declarativo y abstracto, y que se ejerce por parte de los órganos encargados del control de constitucionalidad cuando les es sometido (bien por los sujetos legitimados en cada caso, bien con carácter preceptivo) un texto normativo, con anterioridad a su entrada en vigor.

Asimismo, el análisis de la experiencia española del RPI hasta su supresión en 1985 permite apreciar, además del ya mencionado carácter jurisdiccional del mismo, la tendencia a subrayar, en los diversos balances realizados, los inconvenientes del mismo minimizando o no haciendo notar sus ventajas ${ }^{11}$. En efecto, el RPI fue objeto en su momento de repetidas críticas, referidas sobre todo a la posible extralimitación en sus funciones del Tribunal Constitucional, que quedaría convertido en una suerte de tercera Cámara, al supuesto mayor riesgo de politización, y al no menor peligro de que sea utilizado por las minorías con una finalidad obstruccionista, retrasando indefinidamente la entrada en vigor de la norma impugnada ${ }^{12}$. Tales riesgos quedan claramente reflejados en el citado trabajo de

diferenciándose concretamente «según que el control se lleve a cabo antes o después de la promulgación de la ley» (pág. 61).

Como ejemplo de reflexión sobre el modelo europeo de control de constitucionalidad, incidiendo de nuevo en el ámbito de las clasificaciones, «siempre opinables» (pág. 48), véase T. GroppI, «¿Existe un modelo europeo de Justicia Constitucional?», Revista de Derecho Político, n. ${ }^{\circ}$ 62, 2005, págs. 33-54, en concreto pág. 48.

${ }^{11}$ Encontramos una excepción a esta tendencia, respecto de la STC 76/1983, de 5 de agosto, que resuelve los RPI acumulados contra la LOAPA. Esta sentencia ha sido considerada como un punto a favor del recurso previo, por haber ayudado a resolver jurídicamente un importante conflicto jurídico-constitucional al menor coste posible. Véase una valoración en términos positivos de esta sentencia (a pesar de la posición netamente crítica respecto de la figura del RPI) en J. PÉrEZ Royo, «Crónica de un error: el recurso previo de inconstitucionalidad contra leyes orgánicas», cit., págs. $150 \mathrm{y}$ ss.

12 Por ejemplo, para F. Rubio Llorente («La jurisdicción constitucional en España», en La forma del poder. Estudios sobre la Constitución, Madrid, Centro de Estudios Políticos y Constitucionales, 3. . ed., 2012, vol. III, pág. 1223), el control previo de inconstitucionalidad previsto en la LOTC para las leyes orgánicas fue «utilizado sobre todo a partir del inicio de la segunda legislatura (octubre de 1982) como una especie de veto suspensivo a disposición de la minoría parlamentaria». En su estudio «Tendencias actuales de la jurisdicción constitucional en Europa» (en La forma del poder, cit., págs. 1383-1384) señala, entre las «importantes limitaciones» y como «lado oscuro» del control preventivo, especialmente en el contexto francés, «la 
Pérez Royo, quien habla de los «peligros de los que debe huir la justicia constitucional en un Estado democrático», señalando que tales peligros «resultan mucho más difícilmente soslayables para un TC en un control preventivo que en otro a posteriori» ${ }^{13}$.

Los aspectos positivos podrían concretarse en la mayor seguridad jurídica que aporta (cuando la norma entra en vigor ha sido ya objeto de control), y además, sin que ésta haya sido aún aplicada (evitándose así el problema a veces irresoluble de reparar los efectos producidos por la norma que después es declarada inconstitucional). En efecto, el mejor prevenir que curar resulta especialmente cierto cuando las materias a las que afecte la inconstitucionalidad estén relacionadas, por ejemplo, con derechos fundamentales ${ }^{14}$. A ello habría que añadir la mayor sencillez y eficacia: el ordenamiento no sufre ninguna repercusión por causa de la declaración de inconstitucionalidad, y no se crea ninguna laguna en el tejido normativo, eliminándose así la problemática relativa a los efectos temporales de la sentencia. Dado que, además, parece quedar claro que el recurso previo y el control sucesivo (recurso y cuestión de inconstitucionalidad) no son dos competencias diferentes del Tribunal Constitucional, sino dos formas, modos o mecanismos de llevar a cabo una misma función (el control de constitucionalidad), parece exagerado descartar cualquier modalidad de control previo por el hecho

inatacabilidad de las leyes existentes, que ni los ciudadanos pueden impugnar, ni los jueces poner en cuestión». En cuanto a la combinación de los controles previo y sucesivo que se da en otros países, «no puede eliminar otros defectos del sistema, especialmente el que viene de situar al Tribunal Constitucional en el centro de la arena política, con cuanto ello supone de riesgo para su autoridad».

Por su parte, A. SÁnChez de Vega García («Acerca del recurso previo de inconstitucionalidad», cit., págs. 70-71) entiende, en relación con el recurso previo, que «la tentación del Tribunal de vincular al Parlamento a una determinada interpretación o de corregir u orientar pro futuro el contenido del proyecto de ley impugnado, acabará condicionando la autonomía de las cámaras e invadiendo su esfera».

13 «Si la casi totalidad de los sistemas de control de constitucionalidad han optado por un control a posteriori, a pesar de las ventajas que aparentemente ofrece el principio de más vale prevenir que curar, es precisamente por esto: por la imposibilidad casi absoluta en la práctica de que un TC no acabe cayendo en la tentación de invadir la esfera del legislador, trastocando el equilibrio entre los poderes del Estado diseñado por el constituyente. Frente a una ley ya vigente la prudencia del TC tiene que ser forzosamente muy superior a la que necesita para enjuiciar un proyecto que todavía tiene que entrar en vigor. Asimismo, la tentación de corregir al legislador es más fácilmente resistible en un caso que en otro. La experiencia española del RPI no ha hecho sino confirmarlo» (J. PÉrez Royo, «Crónica de un error: el recurso previo de inconstitucionalidad contra leyes orgánicas», cit., pág. 158).

${ }_{14} \mathrm{Al}$ respecto, A. J. Gómez MonToro, «El control previo de constitucionalidad de proyectos de Estatutos de Autonomía y demás leyes orgánicas», cit., pág. 172. 
de que la experiencia del RPI posible hasta 1985 en virtud del primitivo art. 79 LOTC arrojara más sombras que luces ${ }^{15}$.

Seguramente por ello, y según hemos anticipado, la compleja dinámica de reformas estatutarias emprendidas en España a partir de 2006, en cuyas profundas implicaciones jurídicas y políticas no es posible ahora detenerse ${ }^{16}$, ha propiciado, entre otras muchas consecuencias, que el control previo de constitucionalidad haya vuelto a entrar en escena y a convertirse en objeto de atención. De la reapertura del debate en torno al mismo nos ocuparemos en el apartado siguiente.

15 Durante el período de vigencia del RPI, el Tribunal Constitucional dictó un total de siete sentencias en resolución de recursos previos (mantenemos la expresión «texto definitivo del proyecto de ley orgánica» por ser la utilizada por el Tribunal Constitucional, incorrectamente en nuestra opinión como posteriormente se indicará): STC 38/1983, de 16 de mayo, que resuelve (desestimándolo) el RPI promovido por 55 diputados contra el texto definitivo del proyecto de Ley orgánica por la que se modifican determinados artículos de la Ley 39/1978, de 17 de julio, de elecciones locales; STC 76/1983, de 5 de agosto, que resuelve varios RPI acumulados (promovidos por el Gobierno vasco, Parlamento vasco, Consejo Ejecutivo de la Generalidad de Cataluña, Parlamento de Cataluña y cincuenta diputados) contra el texto definitivo del proyecto de Ley orgánica de armonización del proceso autonómico (LOAPA). La sentencia estima parcialmente el recurso, declarando que la LOAPA no podía promulgarse ni como ley orgánica ni como ley armonizadora, señalando además la inconstitucionalidad de varios de sus preceptos; STC 72/1984, de 14 de junio, que declara inconstitucional el texto definitivo del proyecto de Ley orgánica de incompatibilidades de diputados y senadores (el RPI había sido interpuesto por 53 senadores); la STC 53/1985, de 11 de abril resuelve el RPI interpuesto por 54 diputados contra el texto definitivo del Proyecto de ley orgánica de reforma del artículo 417.bis del Código Penal. La sentencia declara la inconstitucionalidad del texto por incumplir exigencias derivadas del artículo 15 de la Constitución. El Tribunal resolvió con empate a seis votos y fue necesario el voto de calidad del Presidente. La sentencia tuvo cinco votos particulares; STC 66/1985, de 23 de mayo, que resuelve el RPI interpuesto por 54 diputados contra el texto definitivo de la proposición de Ley orgánica derogatoria del capítulo II del Título IV de la Ley Orgánica 2/1979 de 3 de octubre, reguladora del Tribunal Constitucional, que suprime el recurso previo de inconstitucionalidad. El recurso fue desestimado (y por tanto, el RPI suprimido, por la que sería la Ley Orgánica 4/1985 de 7 de junio). Tras la supresión del RPI, el Tribunal dictó dos sentencias más en resolución de recursos previos pendientes: STC 77/1985, de 27 de junio, que estima parcialmente el recurso promovido por 53 diputados contra el texto definitivo del proyecto de Ley orgánica reguladora del derecho a la educación (LODE); y STC 98/1985, de 29 de julio, que desestima los RPI acumulados, promovidos por el Parlamento vasco, el Gobierno vasco y 75 diputados, contra el texto definitivo del proyecto de Ley orgánica de libertad sindical.

${ }_{16}$ Puede verse, como ejemplo de aportación doctrinal en aquellos momentos, situando dicha problemática en sus coordenadas históricas, S. MUÑOZ MACHADO, El problema de la vertebración del Estado en España (Del siglo XVIII al siglo XXI), Madrid, Iustel, 2006. 


\section{EL DEBATE SOBRE LA NECESIDAD DE SU RECUPERACIÓN}

La tendencia a rescatar del olvido el desaparecido recurso previo de inconstitucionalidad, se halla directamente relacionada con los recelos y prevenciones generados por el controvertido proceso de reformas de Estatutos de Autonomía que se vivió en España durante la VIII Legislatura, iniciada el 22 de abril de 2004. En una traducción muy libre de lo sucedido en aquellos años, no resultaba difícil detectar un serio temor - fundado, por lo demás- a que, ante la imposibilidad de alcanzar el consenso necesario para modificar la Constitución en un ambiente político crispado y enrarecido, se pretendiera modificar el modelo territorial constitucionalmente previsto por el atajo o puerta falsa consistente en utilizar para ello la vía de la reforma estatutaria; lo cual equivalía sencillamente a comenzar la casa por el tejado, habida cuenta de que, si realmente se quería y/o necesitaba modificar el modelo territorial, lo lógico y deseable habría sido modificar primero la Constitución (una vez que el contenido de la reforma hubiera alcanzado un grado de maduración y de acuerdo por entonces - y aún hoy_ impensables), y adecuar después los Estatutos al nuevo marco constitucional.

Remontándonos un poco más atrás, podemos convenir en que los síntomas del renovado interés por el control previo comenzaron en 2003, es decir, dieciocho años después de su supresión. En ese momento, el Gobierno del Partido Popular trabajó con la posibilidad de establecer alguna modalidad de control previo, entre otras posibles iniciativas jurídicas encaminadas a impedir que prosperara la reforma del Estatuto de Autonomía del País Vasco conocida como Plan Ibarretxe ${ }^{17}$. El mismo partido, como más adelante se verá, retomó la pretensión de reinstaurar el recurso previo en enero de 2006, a través de varias enmiendas presentadas durante la tramitación de la reforma de la LOTC que entonces se llevaba a cabo, y en el contexto de un conjunto de propuestas realizadas por su presidente nacional, Mariano Rajoy, durante la tramitación parlamentaria de

17 El Gobierno central, del Partido Popular en aquel momento, con base en los artículos 161.2 CE y 76 y 77 LOTC, impugnó ante el Tribunal Constitucional el acuerdo del Gobierno Vasco por el que se aprobaba la «Propuesta de Estatuto Político de la Comunidad de Euskadi», y el de la Mesa del Parlamento Vasco de 4 de noviembre de 2003, por el que se admitía a trámite la propuesta de reforma. El recurso fue inadmitido por el Tribunal Constitucional mediante el Auto 135/2004 de 20 de abril, al que más adelante se aludirá. A propósito de este episodio, O. SALAZAR BeníteZ, «Sobre la inconveniencia de introducir el recurso previo de inconstitucionalidad en los procedimientos de reforma estatutaria», en P. PÉrez Tremps (Coord.), La reforma del Tribunal Constitucional. Actas del V Congreso de la Asociación de Constitucionalistas de España, Valencia, Tirant lo Blanch, 2007, págs. 459-485, en concreto págs. 466 y ss. 
la reforma del Estatuto catalán ${ }^{18}$. En todo caso, reclamaba Rajoy que el referéndum sobre el mencionado texto no se llevara a cabo sin que el Tribunal Constitucional se hubiera pronunciado sobre su adecuación a la Carta Magna. Las propuestas del Partido Popular en torno al tema que nos ocupa se materializaron en la presentación de una Proposición de Ley Orgánica «por la que se establece el control previo de inconstitucionalidad de los Estatutos de Autonomía», publicada en el Boletín Oficial de las Cortes Generales de 21 de abril de $2006^{19}$.

Mayor relieve institucional cobró la reivindicación del recurso previo cuando fue el propio Consejo de Estado el que se refirió a su conveniencia, si bien de modo incidental, dentro del Informe sobre modificaciones de la Constitución Española, aprobado el 16 de febrero de 2006, en el que el «supremo órgano consultivo del Gobierno» (artículo $107 \mathrm{CE}$ ) se pronunció sobre las pretendidas reformas constitucionales anunciadas por el entonces presidente del Gobierno español, José Luis Rodríguez Zapatero, al inicio de la Legislatura. En lo que ahora nos ocupa, señalaba el Consejo de Estado:

«Para concluir este análisis de los aspectos procedimentales de la apertura del sistema de distribución de territorial del poder, parece razonable hacer una

18 Entre ellas, tal y como en su momento recogió la prensa, la polémica y cuando menos novedosa medida consistente en promover, mediante iniciativa legislativa popular, la convocatoria de un referéndum a nivel nacional en torno al nuevo Estatuto catalán, al entender que éste suponía una alteración del modelo territorial de Estado constitucionalmente previsto. Al respecto, Natalia Junquera y Nuria Tesón, en El País, 25 de enero de 2006, pág. 15, y Cristina DE LA Hoz, $A B C, 25$ de enero de 2006, pág. 10. Un nuevo conjunto de catorce medidas encaminadas a la reforma constitucional del modelo territorial, fueron presentadas por el Presidente del Partido Popular, en la clausura de la Conferencia de dicho partido sobre el modelo de Estado, el 2 de diciembre de 2006. Entre ellas, elevar a dos tercios la mayoría necesaria para reformar Estatutos de Autonomía, tanto en los parlamentos regionales como en las Cortes Generales.

19 Boletín Oficial de las Cortes Generales. Congreso de los Diputados. VIII Legislatura. Serie B: Proposiciones de Ley, 21 de abril de 2006. Dicha proposición, encaminada a la inclusión de un nuevo artículo 79 LOTC, dentro de un Título VI dedicado al «Control previo de constitucionalidad», se estudia en varias de las comunicaciones presentadas al V Congreso de la Asociación de Constitucionalistas de España, como las de O. Salazar Benítez ( Sobre la inconveniencia de introducir el recurso previo de inconstitucionalidad en los procedimientos de reforma estatutaria», págs. 459-485) e I. M. GIMÉNEZ SÁNCHEZ ( «Recurso previo de inconstitucionalidad contra proyectos de reforma de Estatutos de Autonomía: viabilidad jurídica de una necesidad política», págs. 355-388), así como en un plano contextual por J. TAJADURA TEJADA («Reformas estatutarias y control previo de constitucionalidad», págs. 487-503). Todas ellas publicadas en el citado libro colectivo P. PÉrez Tremps (Coord.), La reforma del Tribunal Constitucional. Actas del V Congreso de la Asociación de Constitucionalistas de España, Valencia, Tirant lo Blanch, 2007. 
reflexión sobre el papel que en ese procedimiento debería jugar el Tribunal Constitucional. Como antes se indicó, es obvio que el ámbito competencial de muchas de nuestras Comunidades está cerca de agotar el campo que el artículo 149 les reserva, cuando no lo ha agotado ya, y que esta situación incrementa el riesgo de que una nueva ampliación traspase los límites que ese artículo establece. Aunque las eventuales transgresiones podrán siempre ser corregidas por el Tribunal Constitucional a través del recurso de inconstitucionalidad e incluso, aunque con más dificultad, a través de la cuestión de inconstitucionalidad o del recurso de amparo, este control a posteriori tal vez no resulte el más adecuado para fuentes normativas que, como los Estatutos, subordinados a la Constitución, ocupan bajo ella el más elevado lugar en la jerarquía ordinamental. Para librarlos de la sospecha de inconstitucionalidad y, a fortiori, de la acusación explícita de incurrir en ella, podría considerarse la conveniencia de reintroducir el recurso previo de inconstitucionalidad. Un recurso que, como es obvio, a diferencia de la consulta antes sugerida en relación con las reformas estatutarias sin contenido competencial, sólo cabría presentar frente al texto aprobado por las Cortes Generales» ${ }^{20}$.

El control previo estuvo, incluso, en boca del Tribunal Constitucional, en este caso para recordar su inexistencia en aquel momento respecto de los Estatutos de Autonomía, como puede leerse en el Auto 85/2006 de 15 de marzo. En él se inadmite a trámite un recurso de amparo (con base en el artículo 42 LOTC por presunta vulneración del artículo 23.2 CE) interpuesto por el Grupo Parlamentario Popular del Congreso, contra el Acuerdo de la Mesa de dicha Cámara de 18 de octubre de 2005, en el que se califica la propuesta de reforma del Estatuto catalán presentada por el Parlamento de Cataluña como propuesta de reforma de ese Estatuto de Autonomía, al entender los recurrentes que se trataba más bien de una reforma constitucional encubierta.

El Alto Tribunal resume en el Fundamento Jurídico 9 del citado auto, cuyo párrafo más significativo transcribimos a continuación, la postura defendida a lo largo del mismo (véanse en particular los FFJJ 2, 3) y apoyada a su vez en resoluciones anteriores (autos 135/2004 de 20 de abril y 515/2005 de 19 de diciembre):

«En definitiva, bajo la cobertura de un recurso de amparo (y bajo la alegación de vulneración del artículo 23.2 CE, que hemos visto que no se ha producido) lo que realmente se pretende, en el fondo, desvirtuándose claramente nuestro proceso de amparo, es que este Tribunal ejerza una competencia de

${ }^{20}$ Consejo de Estado, Informe sobre modificaciones de la Constitución española, febrero 2006, págs. 217-218. El texto completo puede consultarse en www.consejo-estado.es. Véase también el comentario al mismo por J. M. Bilbao Ubillos, «El informe del Consejo de Estado sobre la Reforma de la Constitución», Revista General de Derecho Constitucional, n. ${ }^{\circ}$ 1: Reforma de los Estatutos de Autonomía y Pluralismo Territorial, Madrid, Iustel, 2006, págs. 153-169. 
control previo de constitucionalidad sobre proyectos de normas, que de ninguna manera tiene. El cumplimiento estricto de la Constitución y de nuestra Ley Orgánica nos obliga a velar porque no se desvirtúen la naturaleza y contenido de los procesos constitucionales que nos están atribuidos, conforme declaramos en el ATC 515/2005, de 19 de diciembre (FJ 3).»

En suma, la postura mayoritaria de los magistrados del Tribunal Constitucional, contenida en los mencionados fundamentos jurídicos implica una negativa a entrar a analizar, en el seno de un recurso de amparo, si un texto que se somete a tramitación parlamentaria vulnera la Constitución (que era lo que alegaban los recurrentes al entender que se trataba de una reforma constitucional encubierta). A este respecto, téngase en cuenta que ni siquiera el RPI que preveía el artículo 79 LOTC permitía (a pesar de utilizar la palabra "proyecto» en diversas ocasiones) que el Tribunal pudiera entender de proyectos o proposiciones de ley, sino únicamente de textos definitivos, cuya tramitación parlamentaria hubiera finalizado, y listos para ser sometidos, en su caso, a referéndum. Por eso, en el FJ 2 del mismo auto 85/2006, puede leerse:

«En cuanto a la vulneración de la Constitución por proyectos de Estatutos de Autonomía, en nuestro ATC 135/2004, de 20 de abril, negamos terminantemente la idoneidad objetiva para que un proyecto de norma pudiera de por sí vulnerar la Constitución y la posibilidad de que este Tribunal interfiriese en el debate parlamentario en una especie de recurso previo. Quiebra así esta primera base conceptual del planteamiento del recurrente ${ }^{21}$.»

${ }^{21}$ Recordemos, sin embargo, que el auto 85/2006 fue objeto de cinco votos particulares. Cabe destacar aquí el formulado por el magistrado Jorge RodríGuez-Zapata PÉREZ, que alude en varias ocasiones al concreto aspecto problemático que ahora nos ocupa. Así, en el punto 3 indica: «El Auto de la mayoría insiste, no obstante, en demostrar reiterativamente que no se debe confundir el recurso de inconstitucionalidad con el recurso de amparo. Se repiten por ello, en un extenso fundamento jurídico 3, los razonamientos que llevaron a rechazar la admisión a trámite de la impugnación de la propuesta de reforma del Estatuto del País Vasco, conocida como plan Ibarretxe, en el ATC 135/2004, de 20 de abril. En el fundamento final (FJ 9) se vuelve a enseñar, todavía, que bajo la cobertura de un recurso de amparo lo que realmente se pretende en el fondo $[\ldots .$.$] es que este Tribunal ejerza una competencia de control previo de inconstitucionalidad sobre$ proyectos de normas que de ninguna manera tiene [...]. Este planteamiento no se corresponde con lo que se pide en la demanda y dificulta la comprensión real del problema suscitado en este proceso de amparo». Y más adelante (punto 10) este mismo magistrado recordará: «He escrito — no para este caso sino hace ya años, y en sede científica - que la abolición de este control constitucional previo (aunque luego fuera confirmada por la STC 66/1985, de 23 de mayo, FJ 3) ha sido un factor negativo para las garantías de nuestra Constitución de 1978».

Por su parte, el magistrado Ramón Rodríguez Arribas, alude en su voto particular (punto 7) al riesgo que conlleva (habida cuenta de que ya no existe en el ordenamiento español el recurso previo de inconstitucionalidad) el hecho de que el Tribunal Constitucional, para pronun- 
Siendo este el caldo de cultivo, no es de extrañar que, paralelamente al ámbito institucional, el control previo volviera a ser objeto de atención en el plano doctrinal. Valgan como ejemplo las reflexiones de Aragón Reyes sobre la construcción del Estado autonómico; el cual, presentaría, entre otras características, «una decisiva y permanente intervención del Tribunal Constitucional para reducir la complejidad y equilibrar el sistema».

«En relación con esto último — continúa Aragón— la posibilidad de recuperar el control previo de constitucionalidad para la reforma de los Estatutos de Autonomía (sugerida también en el Informe del Consejo de Estado) debería ser objeto de una ponderada reflexión (y no sólo porque en algunos Estatutos intervenga el referéndum de los ciudadanos de la Comunidad Autónoma, sino también, y sobre todo, por la especial posición y el relevante significado que tienen los Estatutos en nuestro modelo constitucional) $)^{22}$.»

Asimismo, y en referencia específica al tema, Cruz Villalón, que ya se había ocupado en su momento de esta figura ${ }^{23}$, retomó la materia y, junto con «algunas buenas razones para recuperar el control previo», apunta también sus «dificultades objetivas» en el sentido de que, para dar por bueno el control previo no basta con poner de manifiesto sus ventajas, sino también valorar los inconvenientes que puede plantear en determinadas circunstancias ${ }^{24}$.

ciarse sobre una iniciativa legislativa que afecte a principios esenciales de la Constitución Ly por tanto, añadimos, venga a ser una reforma constitucional encubierta], deba esperar no solo a que el procedimiento legislativo haya concluido, sino además a que sea interpuesto un recurso o una cuestión de inconstitucionalidad sobre el texto ya vigente, cuando dicho texto haya podido ya desplegar efectos.

${ }^{22}$ M. Aragón, «La construcción del Estado autonómico», en Revista General de Derecho Constitucional, n. ${ }^{\circ}$ 1: Reforma de los Estatutos de Autonomía y Pluralismo Territorial, Madrid, Iustel, 2006, págs. 15-38, en concreto pág. 38. A pie de página añade el propio autor: «Esa razón también valdría para plantearse la conveniencia de ampliar ese hipotético control previo a las reformas constitucionales e incluso a las reformas de la Ley Orgánica del Tribunal Constitucional».

${ }^{23}$ P. Cruz Villalón, «El control previo de constitucionalidad», Revista de Derecho Público (2. época), n. ${ }^{\circ} 82,1981$, págs. 5-21.

${ }^{24}$ Pedro CruZ Villalón, «El control previo, a los veinte años de su supresión», en Juan Luis Requejo Pagés (Coord.): La rebelión de las leyes. Demos y nomos: la agonía de la justicia constitucional, Fundamentos. Cuadernos monográficos de Teoría del Estado, Derecho Público e Historia Constitucional, n. 4/2006, Junta General del Principado de Asturias, págs. 277-290. El texto es, además, la contribución del autor al Libro Homenaje a Louis Favoreu.

Contempla este autor (págs. 287 y ss.) «una posible alternativa al modelo vigente desde 1985», y concluye (pág. 290) que «no faltan razones para que el caso singular de control previo que en este momento suponen los tratados internacionales, y tal como aparece hoy previsto en el artículo 95 de la Constitución, dejase de ser un supuesto excepcional y único, de tal modo que, con las cautelas y modificaciones señaladas, se abriera a los casos de las reformas de la Cons- 
La necesidad de rescatar del olvido el recurso previo, y no solo para los Estatutos de Autonomía, venía reivindicada también por la tardanza con que se verifica el sucesivo (en ocasiones años después de la interposición del correspondiente recurso), lo cual le hace perder su sentido (incluso podría ocurrir que la ley recurrida hubiera sido ya derogada). En este sentido, una eventual tardanza en la resolución de un recurso previo, sin perjuicio de las disfuncionalidades que pudiera comportar, o de la finalidad obstaculizadora con que pudiera ser utilizado, no tendría, al menos el inconveniente de los posibles efectos desplegados por el texto vigente declarado inconstitucional ${ }^{25}$. En esta línea, De Esteban señalaba el doble objetivo que cumplía el recurso previo regulado en el artículo 79 de la LOTC: «Por un lado, que [los Estatutos de Autonomía] no fuesen declarados inconstitucionales cuando ya estuviesen surtiendo efectos jurídicos. Y por otro, que en el caso de los proyectos de Estatuto del artículo 151, el control debería hacerse, para no defraudar al cuerpo electoral respectivo, antes de que se celebrara el referéndum exigido». Critica, por ello, que «al suprimirse torpemente este artículo, se estaban sembrando las futuras discordias que hoy ya han germinado. Las consecuencias son que en estos tres años se han aprobado muchas disposiciones de desarrollo del Estatuto, y no resultará fácil, en su caso, dar marcha atrás» ${ }^{26}$.

Por su parte, García Roca se expresa en los siguientes términos: «Con seguridad no se debió suprimir del artículo 79 de la LOTC el recurso previo contra propuestas de reforma de los Estatutos al tiempo de suprimir acertadamente el mismo recurso contra leyes orgánicas que había desatado prácticas de obstruccionismo parlamentario. Que el Tribunal Constitucional se vea obligado a revisar la constitucionalidad de una ley refrendada es procesalmente posible, pero constituye un regalo envenenado que podría perfectamente evitarse incorporando un control previo de los Estatutos antes de su entrada en vigor» ${ }^{27}$.

Cerrando esta panorámica, leemos a Solozábal Echavarría, para quien «la propuesta de reintroducción del recurso previo no debería encontrar la oposición

titución y de los Estatutos de Autonomía. Tal ampliación no desnaturalizaría la opción básica por el control sucesivo y contribuiría seguramente a reforzar la garantía jurisdiccional de la Constitución normativa».

${ }^{25}$ Cfr. M. A. Alegre Martínez, Justicia constitucional y control preventivo, cit., págs. 282 y ss.

26 J. De Esteban, «El pronunciamiento catalán», Diario El Mundo, 26 de noviembre de 2009.

27 J. García Roca, en la «Encuesta sobre el Estado autonómico» publicada en Teoría y Realidad Constitucional, n. ${ }^{\circ}$ 24, UNED, 2009, págs. 11-105, en concreto pág. 94. Como más adelante veremos, las Leyes Orgánicas plantean, en caso de ser declaradas inconstitucionales a posteriori, la misma problemática que los Estatutos en cuanto a la difícil o imposible reparación de los efectos producidos, y además en algunos casos con la implicación de derechos fundamentales. 
de argumentos sistemáticos o lógicos frente a la misma, fuera de los supuestos de utilización de las instituciones contra natura ${ }^{28}$.

Ocurre, sin embargo, que, por más que se volviera la mirada hacia el control previo como posible instrumento de control de constitucionalidad de las reformas estatutarias, el análisis que al respecto pudiera llevarse a cabo acabaría tarde o temprano encontrándose frente a frente con los temores y prejuicios que siempre han lastrado al control previo (fundamentalmente, y como se adelantó en el apartado anterior, el supuesto mayor riesgo de politización, y el peligro de su utilización con finalidad obstruccionista). Es, en efecto, habitual, que las referencias al control previo hagan especial hincapié en sus inconvenientes, e incluso cuestionen su legitimidad como instrumento de fiscalización de la constitucionalidad ${ }^{29}$.

${ }^{28}$ J. J. SolozÁbal Echavarría, «El Estatuto de Cataluña ante el Tribunal Constitucional», Teoría y Realidad Constitucional, n. ${ }^{\circ}$ 24, UNED, 2009, págs. 173-190, en concreto pág. 179. Reflexiona el autor sobre el momento en que debería ejercerse ese control en caso de ser reintroducido: «si se hace después del voto de los ciudadanos y antes de la sanción, la consecuencia será, en efecto, que no pasará al ordenamiento una norma inconstitucional, cortándose el paso también al desarrollo de aspectos que resulta que se basan en una norma inconstitucional. Pero el problema político de oponer el Tribunal a la decisión de los ciudadanos de la Comunidad Autónoma, aunque jurídicamente sea una cuestión sencilla, no se habrá evitado. Más cuestionable es si la impugnación del Estatuto se hace eludiendo el voto de los ciudadanos, porque se ha eliminado esta fase de la tramitación estatutaria, o dicha impugnación se lleva a cabo en relación con la decisión de las Cortes Generales verificada antes de la consulta ciudadana. En tales casos, sobre todo si se impide que la consulta culmine la tramitación de la reforma estatutaria, nos encontramos ante una modificación sustancial, y a mi juicio inconveniente, de la ordenación autonómica en un aspecto capital de la misma como es la reforma estatutaria». Como bien señala este autor, conviene evitar que el Tribunal Constitucional tenga que pronunciarse sobre el texto ratificado por el cuerpo electoral en referéndum. Y la única manera de lograrlo es que el texto sometido a control previo del Tribunal Constitucional sea el definitivamente aprobado por el Parlamento. No parece que ello acarree los inconvenientes que el autor citado plantea (y en todo caso, serían un mal menor en comparación con el que se trata de evitar): si el texto aprobado por el Parlamento resulta ser contrario a la Constitución, no tiene sentido ya someterlo a referéndum: no tendría sentido que los ciudadanos dieran por bueno un texto contrario al texto constitucional (la única manera en la que ello sería posible sería en un referéndum de reforma constitucional, pero no con ocasión de una reforma estatutaria).

29 Encontramos un ejemplo de ello en el trabajo de G. BouZat, «La argumentación jurídica en el control de constitucionalidad. Una comparación entre la judicial review y el control preventivo y abstracto de constitucionalidad (A propósito de la Sentencia 24-493 de la Corte Suprema Argentina, caso Iachemet, M. ${ }^{a}$ L. vs. Armada Argentina)», Revista Española de Derecho Constitucional, n. ${ }^{\circ}$ 54, 1998, págs. 273-285: «El control preventivo y abstracto de constitucionalidad, en manos de un Tribunal Constitucional, que analiza las normas sin tener en cuenta la incidencia de la aplicación de las mismas en un caso particular, se maneja en un grado de abstracción similar al que tuvo en cuenta el legislador al sancionador la ley [sic]. Dicho tipo de control implica una suerte de elitismo que presupone que un reducido grupo de expertos están mejor capacitados que el Parlamento para solucionar los conflictos valorativos que plantea la declaración de inconstitucionalidad de una ley. 
Por si todo ello fuera poco, una eventual recuperación del RPI tenía otro factor en contra: con carácter general, y como es sobradamente sabido, el control previo, en cuanto mecanismo que la oposición puede utilizar para promover el control de constitucionalidad de las leyes, molesta a quien gobierna y a la mayoría que le apoya, y satisface a las minorías, como se demostró a lo largo del episodio que culminó con su supresión en 1985. En el otro platillo de la balanza está el hecho de que la Constitución no excluye la posibilidad de que el control de constitucionalidad se ejerza con carácter preventivo (recordemos a este respecto que en el artículo $95 \mathrm{CE}$, y en su desarrollo ex artículo 78 LOTC se contempla el control con carácter preventivo respecto de los tratados internacionales); y que, como se vio al comienzo del apartado anterior, la inconstitucionalidad del RPI no quedó afirmada en la STC 66/1985. Pues bien: este es el escenario en el que el recurso previo ha tenido que abrirse camino para regresar al artículo 79 de la LOTC, en los términos que trataremos de explicar a continuación.

\section{ANTECEDENTES INMEDIATOS: LAS PROPOSICIONES DE LEY ORGÁNICA DE 24 DE ENERO DE 2014}

El parcial retorno del RPI vino precedido del registro, el 24 de enero de 2014, de sendas proposiciones de reforma de la Ley Orgánica del Tribunal Constitucional por parte de los Grupos parlamentarios socialista y popular en el Congreso de los Diputados. En ambas se aboga por recuperar esta figura únicamente para controlar con carácter preventivo, bien los Estatutos de Autonomía,

A mi entender, se le debe otorgar prioridad a la decisión legislativo [sic] porque cuenta con mayor legitimidad democrática. A pesar de que en ciertos casos pueda surgir una clara contradicción entre una ley y la Constitución, ello no es lo que ocurre en la mayoría de los casos, especialmente en los casos difíciles, siguiendo la terminología de Dworkin» (pág. 281).

También L. Pegoraro se ha referido al mayor grado de abstracción del control previo (el Tribunal constitucional tendrá que juzgar sobre «casos meramente abstractos relativos a hechos que no se dan en la vida cotidiana»), así como al hecho de que la ley no haya sido aún aplicada, lo que conlleva la «exigencia de someter las disposiciones legislativas a la prueba de interpretación». Además, se refiere este autor a la imposibilidad de posterior juicio de una ley que haya sido declarada conforme a la Constitución en la vía previa, para concluir que «el control preventivo pretende insistir en el significado unívoco de una ley o de una parte de ella, pero no tiene en cuenta los restantes, presentes y futuros» («La circulación, la recepción y la hibridación de los modelos de Justicia constitucional», Anuario Iberoamericano de Justicia Constitucional, n. ${ }^{\circ}$ 6, 2002, págs. 393416, en concreto págs. 404-405. Traducción de Francisco Fernández Segado, a partir de un texto inicial de Rafael Rubio NúÑEZ, revisado y modificado.

En respuesta a estas objeciones, M. A. Alegre Martínez, Justicia constitucional y control preventivo, cit., págs. 177 ss. y 261 ss. 
bien sus reformas, o bien unos y otras («Propuestas de Reforma de los Estatutos de Autonomía» en la proposición socialista; «Proyectos de Estatutos de Autonomía o propuestas de reforma de los mismos» en la popular ${ }^{30}$ ). Ambas denominaciones son inexactas pues, como se verá, lo que se lleva al Tribunal Constitucional no es ningún proyecto sino el texto definitivo aprobado por las Cámaras. En las dos se propone reintroducir el RPI en el art. 79 LOTC (aprovechando que éste había quedado sin contenido en virtud de su derogación por la LO 4/1985 de 7 de junio). Tanto una como otra evitan excesivas complicaciones, en el sentido de que proponen una regulación muy similar a la del originario art. 79 LOTC, y basada a su vez en la del recurso de inconstitucionalidad. Así, en ambas se hace coincidir la legitimación para interponer el RPI con la prevista para el recurso de inconstitucionalidad contra Estatutos de Autonomía, y se contiene una remisión a éste en cuanto a la tramitación del procedimiento.

Existe coincidencia parcial en el texto susceptible de control (que, como acabamos de indicar, no es otro que el texto definitivo del Estatuto o su reforma, tras su tramitación por las Cortes Generales, incluyendo la propuesta socialista únicamente las reformas, y la popular tanto éstas como los nuevos Estatutos), y en el plazo de tres días para interponer el recurso (plazo extremadamente breve «por la naturaleza propia de este recurso», tal y como se especifica en la exposición de motivos que antecede a la propuesta popular). En ésta, se precisa que dicho plazo de tres días empieza a contar «desde la votación final sobre el conjunto del proyecto en el Congreso o desde la votación en el Senado en el caso de que éste no aprobara enmiendas para su ratificación por el Congreso». La propuesta socialista sitúa el inicio del cómputo de los tres días «desde la publicación del texto aprobado en el Boletín Oficial de las Cortes Generales». En ambos casos la interposición del RPI implica

${ }^{30}$ Sin embargo, en la exposición de motivos de la proposición socialista, junto la indicación de que «se propone recuperar el recurso previo para el caso de las Propuestas de Reforma de Estatutos de Autonomía», puede leerse: «Justificada así la necesidad del recurso previo de inconstitucionalidad en relación con los Estatutos de Autonomía...». En el comentario de M. A. Presno LINERA «El regreso del recurso previo de inconstitucionalidad» (https://presnolinera.wordpress. com/2014/01/29/el-regreso-del-recurso-previo-de-inconstitucionalidad/) se encuentran los enlaces para consultar ambas proposiciones: https://presnolinera.files.wordpress.com/2014/01/proposicic3b3n-del-grupo-parlamentario-popular.pdf y https://presnolinera.files.wordpress.com/2014/01/ proposicic3b3n-del-grupo-parlamentario-socialista.pdf. Asimismo se proporciona el enlace correspondiente a las proposiciones y la subsiguiente tramitación de las mismas, en la página web del Congreso de los Diputados: la socialista (n. ${ }^{\circ}$ expediente $122 / 000140 / 0000$ ) y la popular (n. expediente 122/000141/0000): http://www.congreso.es/portal/page/portal/Congreso/Congreso/ Iniciativas?_piref73_2148295_73_1335437_1335437.next_page =/wc/servidorCGI\&CMD=VE RLST $\&$ BASE $=$ IW $10 \&$ FMT $=$ INITXLSS. $f m t \& D O C S=1-25 \& D O C O R D E R=F I F O \& Q U E R Y=\%$ 28122\%2F000207*. EXPD.\%29 
la suspensión de los trámites subsiguientes, incluido el referéndum en el respectivo territorio de la Comunidad Autónoma si éste hubiera de celebrarse. Este extremo aparece expresamente detallado en la proposición popular, según la cual: «el mismo no podrá convocarse hasta que haya resuelto el Tribunal Constitucional y, en su caso, se hayan suprimido o modificado por las Cortes Generales los preceptos declarados inconstitucionales». En esta misma propuesta, para que el recurso sea admitido a trámite, la interposición del mismo debe ser anunciada al Presidente del Congreso. Tampoco procede, una vez interpuesto el recurso, la remisión del texto a efectos de su promulgación o publicación en el BOE.

En términos muy similares se regulan en ambas proposiciones los efectos de la decisión del Tribunal Constitucional, distinguiendo, al igual que se hacía en la versión original de la LOTC, en función de que el recurso sea o no estimado. Así, en la propuesta socialista, si el pronunciamiento del Tribunal declara la inexistencia de inconstitucionalidad en el texto impugnado, «se acordará la continuación de los trámites conducentes a su entrada en vigor, incluido, en su caso, el correspondiente procedimiento de convocatoria y celebración de referéndum»; según la propuesta popular, «seguirá su curso el correspondiente procedimiento». Mientras que si el pronunciamiento del Tribunal declara la inconstitucionalidad del texto impugnado, «deberá concretar ésta y el precepto o preceptos constitucionales infringidos. En este caso, la tramitación del texto no podrá proseguir sin que tales preceptos sean modificados o suprimidos por las Cortes Generales» (propuesta socialista que reproduce prácticamente el párrafo 4.b) del art. 79 LOTC suprimido en 1985). De nuevo es grande el parecido con el texto presentado por el Grupo popular: si el TC declara la inconstitucionalidad, «deberá concretar los preceptos a los que alcanza, aquéllos que por conexión o consecuencia quedan afectados por tal declaración y el precepto o preceptos infringidos. En este supuesto, la tramitación no podrá proseguir sin que tales preceptos hayan sido suprimidos o modificados por las Cortes Generales».

Ambas proposiciones divergen, sin embargo, a la hora de concretar o no determinados extremos (plazo para la resolución del recurso, compatibilidad con el recurso de inconstitucionalidad a posteriori, o inicio de la aplicación de la reforma). Así, a diferencia de la propuesta popular, la firmada por el Grupo socialista establece taxativamente que el RPI deberá ser resuelto «en el inaplazable plazo de seis meses desde su interposición. El Tribunal dispondrá lo necesario para dar cumplimiento efectivo a esta previsión, reduciendo los plazos ordinarios y dando en todo caso preferencia a la resolución de estos recursos sobre el resto de asuntos en tramitación», 
y ello con el fin de impedir «dilaciones indeseables en su resolución», tal y como se argumenta en la exposición de motivos ${ }^{31}$.

Por su parte, la propuesta popular detalla dos aspectos no contemplados en la socialista. En primer lugar, y reproduciendo literalmente el antiguo art. 79.5 LOTC, establece la compatibilidad entre control previo y sucesivo: «El pronunciamiento en el recurso previo no prejuzga la decisión del Tribunal en los recursos que pudieren interponerse tras la entrada en vigor con fuerza de Ley del texto impugnado en la vía previa». En segundo lugar, aunque ambas proposiciones concluyen con la previsión de entrada en vigor en términos parecidos («el día de su publicación en el Boletín Oficial del Estado» la socialista, y «al día siguiente de su publicación» la popular), ésta incluye una Disposición transitoria en virtud de la cual «La presente Ley Orgánica será de aplicación a todos aquellos Estatutos de Autonomía que inicien su tramitación parlamentaria con posterioridad a la entrada en vigor de esta Ley», de manera que el RPI sería inaplicable a las reformas estatutarias cuya tramitación ya estuviera iniciada a su entrada en vigor.

Este extremo nos permite conectar, una vez reseñada la regulación contenida en ambas proposiciones, con la finalidad que pudo mover a ambos grupos a presentarlas, y que en ambos casos podría ir más allá de la justificación expresada en las respectivas exposiciones de motivos. Para los populares, «resulta evidente que los Estatutos de Autonomía deben estar sujetos a la Constitución como garantía de estabilidad y no fricción en la arquitectura jurídico institucional del Estado». Remitiéndose al Informe sobre las reformas de la Constitución Española emitido por el Consejo de Estado en 2006 (al que nos referíamos en el apartado anterior), el cual proponía considerar la conveniencia de reintroducir el recurso previo para librar de sospecha de inconstitucionalidad a los Estatutos, consideran «necesario y conveniente restablecer, adaptándolo a la actual configuración del Estado, el recurso previo de inconstitucionalidad de los Estatutos de Autonomía». No aluden, por tanto, en la exposición de motivos, a la problemática específica que se plantea por el hecho de que una reforma estatutaria sometida ya a referéndum sea sometida con posterioridad al control del Tribunal Constitucional (aunque sí lo tienen en cuenta, como acabamos de ver, cuando, en la redacción propuesta para el nuevo art. 79 LOTC, detallan los efectos de la interposición del recurso). Precisamente en torno a este aspecto del referéndum gira en su mayor parte la motivación aducida por los socialistas. Para ellos, el carácter de norma institucional básica

${ }^{31}$ En la misma puede leerse también a este respecto: «Se evita así el principal reproche que mereció en el pasado esta institución jurídica y que justificó su supresión en 1985: su utilización por los grupos minoritarios para paralizar la entrada en vigor de normas legales válidamente aprobadas por las Cortes Generales y su configuración como factor distorsionador del sistema de relaciones entre los poderes constitucionales del Estado, entre mayorías y minorías». 
que la Constitución (art. 147.1) predica de los Estatutos de Autonomía, «bace que su eventual declaración de inconstitucionalidad, una vez en vigor y desplegando todos sus efectos, pueda producir graves consecuencias tanto jurídicas como políticas y sociales». El hecho de que en la aprobación de los Estatutos de Autonomía intervengan tanto la propia Comunidad como el Estado, y en ocasiones el cuerpo electoral mediante referéndum, da a estas normas una «especial legitimidad», en delicado equilibrio (que es preciso garantizar) con el obligado respeto de dicho texto al marco constitucional. Así las cosas, «se hace necesario evitar el choque de legitimidades que implica que el texto aprobado, incluso ratificado por los ciudadanos mediante el correspondiente referéndum, sea declarado inconstitucional años más tarde, con el perjuicio en términos sociales y políticos que ello puede producir» ${ }^{32}$.

Estas apreciaciones nos ponen sobre la pista de la intencionalidad que subyace en unas iniciativas legislativas que, claro está, no carecen de trasfondo político. Parece que los firmantes de ambas proposiciones (aunque los populares no lo mencionen expresamente) trataban de evitar que se repitiera lo sucedido en Cataluña, donde la STC 31/2010 de 28 de junio en relación con la LO 6/2006, de reforma del Estatuto catalán se produce cuatro años después de que ésta fuera ratificada en el referéndum estatutario de 18 de junio de $2006^{33}$. A ello hay que añadir que las propuestas que comentamos se for-

32 Sin embargo, para I. Villaverde MenÉNDEZ, «El control previo de constitucionalidad de las normas con rango de ley. Crónica de un escéptico», cit., págs. 38-39, estaríamos ante un «falso choque de legitimidades», pues el hecho de que la norma con rango de ley haya sido refrendada «no debilita ni la posición del TC ni hace menos legítima democráticamente su decisión, por más que, desde luego, políticamente el caso sea otro. Someter a control previo una norma antes de ser refrendada evita, claro está, los inconvenientes 'políticos' de su control de constitucionalidad una vez sometida a la consulta popular. Pero no parece que este sea un argumento dogmático o técnico de peso. Cosa distinta es que en estos casos, como puede suceder con los Estatutos de Autonomía, la instauración de un recurso previo deba tener en cuenta, en primer lugar, los posibles solapamientos de plazos que provoque la situación de que la norma impugnada se someta a referéndum dentro del plazo de interposición del recurso previo $[\ldots .$.$] .$

${ }_{33}$ Como se recordará, con una participación del $48,85 \%$, el resultado fue de $73,9 \%$ de votos a favor, $20,76 \%$ en contra y $5,34 \%$ en blanco. Sobre el cuestionamiento de la legitimidad del Tribunal Constitucional para enjuiciar una norma ratificada por el cuerpo electoral en referéndum, escribe Castellà Andreu que «en el fondo, incluso se reabría el debate - apenas presente en España desde que, al inicio del régimen constitucional, el profesor García de Enterría lo dejara clarificado- sobre la supuesta incompatibilidad entre la democracia y la justicia constitucional» («Tribunal Constitucional y proceso secesionista catalán: respuestas jurídico-constitucionales a un conflicto político-constitucional», Teoría y Realidad Constitucional, n. ${ }^{\circ}$ 37, 2016, págs. 561-592, en concreto pág. 566).

Según hemos adelantado en el apartado anterior, el Grupo Popular ya había intentado reinstaurar el recurso previo en enero de 2006 durante la tramitación de la reforma del Estatuto catalán (que coincidía en el tiempo con la de la que sería LO 6/2007, de 24 de mayo, de reforma de 
mulan en un contexto muy determinado: la reforma del Estatuto de Autonomía de Castilla-La Mancha, con mayoría popular durante la VIII Legislatura (2011-2015) en el Parlamento de dicha Comunidad ${ }^{34}$. Sin duda los diputados populares querían que el regreso del RPI que, como hemos visto, proponían para garantizar la sujeción de los Estatutos a la Constitución, no afectara a la reforma del Estatuto de Castilla-La Mancha, de tal manera que pudiera concluir su tramitación y entrar en vigor sin el inconveniente de un eventual recurso previo socialista (como prueba la disposición transitoria incluida en la proposición). Por su parte, el grupo socialista, bajo cuya mayoría en las Cortes Generales se había suprimido el RPI en 1985, se hace en 2014 defensor de su recuperación, precisamente en un momento en el que le interesaba poner trabas a la reforma del Estatuto castellano-manchego ${ }^{35}$.

la. LOTC), para evitar que el TC tuviera que pronunciarse sobre dicha reforma una vez celebrado el referéndum. En aquella ocasión, se preveía una eficacia temporal bien distinta, al proponer en una de las enmiendas planteadas a la reforma de la LOTC (concretamente la relativa a la Disposición final sobre la entrada en vigor) que el recurso previo fuese ya «de aplicación a los proyectos de reforma de Estatutos de Autonomía que estuviesen tramitándose en las Cortes Generales al tiempo de la tramitación parlamentaria de la presente ley y no hubiesen entrado en vigor» (Proyecto de Ley Orgánica por la que se modifica la Ley Orgánica 2/1979, de 3 de octubre, del Tribunal Constitucional, enmienda n. ${ }^{\circ} 81$ presentada por el Grupo Popular en el Congreso. BOCG, Congreso de los Diputados, VIII Legislatura, Serie A, 23/02/2006).

${ }^{34}$ En julio de 2013 las Cortes de Castilla-La Mancha habían aprobado la reforma que quedaría plasmada en la Ley Orgánica 2/2014, de 21 de mayo, de reforma del Estatuto de Autonomía de Castilla-La Mancha (BOE 22 de mayo de 2014). La reforma afecta al artículo 10 cuyo apartado segundo queda redactado así: «La circunscripción electoral es la provincia. Las Cortes de CastillaLa Mancha estarán constituidas por un mínimo de 25 Diputados y un máximo de 35». La anterior regulación recogía un intervalo de 47 a 59 diputados. El grupo parlamentario socialista en el Senado recurrió ante el Tribunal Constitucional esta reducción de parlamentarios entendiendo que vulneraba la exigencia constitucional de proporcionalidad (art. 152.1), así como el pluralismo político (art. 1.1), interdicción de la arbitrariedad de los poderes públicos (art. 9.3) y acceso condiciones de igualdad a funciones y cargos públicos (art. 23.2), entre otros preceptos constitucionales. El recurso de inconstitucionalidad fue desestimado por la STC 197/2014 de 4 de diciembre. Igualmente fue desestimado (STC 15/2015, de 5 de febrero) el recurso presentado por senadores socialistas contra la Ley 4/2014, de 21 de julio, de reforma de la Ley 5/1986, de 23 de diciembre, electoral de Castilla-La Mancha, que concreta en 33 el número de diputados autonómicos.

35 En relación con ello, recuerda I. Astarloa Huarte-Mendicoa que el recurso previo «ya estaba en la ley originaria del Tribunal de 1979, hasta que el Partido Socialista lo eliminó en 1985, tras llegar al Gobierno, habiéndose opuesto desde entonces a recuperarlo, frente a las propuestas presentadas reiteradamente por el Partido Popular. ¿Qué ha cambiado para que los socialistas se hayan caído del caballo casi tres décadas después? Sencillamente, que ahora persiguen el objetivo coyuntural de entorpecer la tramitación de la reforma del Estatuto de Castilla-La Mancha que reduce el número de parlamentarios de aquella Comunidad») («Estatutos de Autonomía y Tribunal Constitucional», Diario $A B C, 13$ febrero 2014, pág. 14). 
En todo caso, y volviendo al plano jurídico que aquí interesa, las proposiciones de Ley Orgánica que comentamos han sido consideradas «inconsistentes con sus motivos», además de "pobres técnicamente», tanto por su regulación como por lo que dejan sin resolver (entre otros extremos, las consecuencias de que las Cortes hagan caso omiso del fallo del TC, y envíen para sanción y promulgación, sin modificar, el texto declarado inconstitucional ${ }^{36}$. Comparativamente, parece más sólida la motivación en la propuesta socialista, y más detallada la regulación sustantiva contenida en la proposición popular (no tanto por estar más o mejor elaborada, cuanto por reproducir más fielmente la versión inicial del RPI de 1979, contenida en el art. 79 LOTC).

Corresponde ahora conocer el devenir de estas dos proposiciones hasta materializarse en la Ley Orgánica 12/2015, respecto de la cual podemos adelantar que fusiona ambas iniciativas recogiendo elementos de una y otra, configurando así el actual RPI, que ha salido de las Cortes Generales minorado y escasamente renovado.

\section{LA LEY ORGÁNICA 12/2015: TRAMITACIÓN, JUSTIFICACIÓN Y CONTENIDO}

Las divergencias entre las dos proposiciones de Ley Orgánica comentadas y los condicionantes políticos que subyacían en torno a su presentación, hicieron necesaria una prolongada negociación entre los dos grupos mayoritarios del Congreso, que concluyó con la subsunción de ambas proposiciones en una sola, la cual acabaría por tomar forma como Ley Orgánica 12/2015 de 22 de septiembre $^{37}$. Hablamos, por tanto, de un largo paréntesis desde que las iniciales proposiciones socialista y popular fueron presentadas, como se ha indicado, el 24 de enero de 2014, hasta que la Ley Orgánica quedó definitivamente aprobada en la sesión del Senado del 10 de septiembre de $2015^{38}$.

Las proposiciones popular y socialista habían sido tomadas en consideración por el Pleno del Congreso en su sesión de 18 de febrero de 2014. Al tener por

36 I. Villaverde MenéndeZ, «El control previo de constitucionalidad de las normas con rango de ley. Crónica de un escéptico», cit., pág. 31.

37 BOE 23 de septiembre de 2015: https://www.boe.es/boe/dias/2015/09/23/pdfs/BOEA-2015-10196.pdf

${ }^{38}$ Ofrecemos aquí una somera síntesis de la tramitación parlamentaria, para cuya consulta en su totalidad puede acudirse al enlace: http://www.congreso.es/portal/page/portal/Congreso/Congreso/Iniciativas?_piref73_2148295_73_1335437_1335437.next_page=/wc/servidorCGI\&CM $\mathrm{D}=\mathrm{VERLST} \& \mathrm{BASE}=\mathrm{IW} 10 \& \mathrm{PIECE}=\mathrm{IW}$ A0 \&FMT $=$ INITXD1S.fmt $\&$ FORM $1=$ INITXLUS $\mathrm{fmt} \& \mathrm{DOCS}=10-10 \& \mathrm{QUERY}=\% 28 \mathrm{I} \% 29$. ACIN1.+\%26+\%28122\%29. SINI. 
objeto la introducción de modificaciones en el mismo texto legal (la LOTC), las Ponencias encargadas de redactar los respectivos Informes sobre las proposiciones y las enmiendas presentadas a las mismas, deciden por mayoría refundir en un solo texto las dos proposiciones, para que se tramiten agrupadamente con un nuevo título y número de expediente ( $P$ Proposición de Ley Orgánica de modificación de la Ley Orgánica 2/1979, de 3 de octubre, del Tribunal Constitucional, para el establecimiento del recurso previo de inconstitucionalidad para los Proyectos de Ley Orgánica de Estatutos de Autonomía o de su modificación», n. expediente: 122/000207). Se acuerda, por tanto, elevar a la Comisión Constitucional del Congreso un único Informe, fechado el 7 de julio de $2015^{39}$. El texto unificado ahí contenido habría de ser ya el definitivo, después de la aprobación por el Pleno del Congreso el 16 de julio (BOCG, Congreso, 23 de julio 2015) y por el del Senado el 10 de septiembre (BOCG, Senado, 14 de septiembre 2015), una vez rechazadas todas las enmiendas y propuestas de veto formuladas. Ello fue así con el voto favorable de los grupos parlamentarios popular y socialista, que habían concluido sus negociaciones con un acuerdo el 25 de junio, desbloqueando así la situación. Los demás grupos parlamentarios votaron en contra basando su rechazo durante la tramitación parlamentaria en los conocidos argumentos que pueden resumirse en el supuesto riesgo de convertir al Tribunal Constitucional en una tercera cámara, y en que el recurso previo no es la solución adecuada para resolver el problema territorial planteado en Cataluña.

El pacto entre los dos grupos mayoritarios tuvo su reflejo tanto en la motivación como en la regulación final de la figura, tal y como se muestra de manera esquemática a continuación:

a) El Preámbulo de la LO 12/2015 resulta ser una síntesis de las respectivas Exposiciones de Motivos de las proposiciones de 2014. Se inicia con un párrafo tomado de la proposición socialista en el que se estima que el Estado Autonómico "ha funcionado razonablemente bien durante los más de treinta y cinco años que la norma fundamental lleva en vigor», erigiéndose "en factor decisivo en la construcción de nuestro Estado Social y Democrático de Derecho». Las siguientes consideraciones sobre el papel conjunto que la Constitución y el Estatuto de Autonomía juegan como «fundamento del orden social y la convivencia política y cívica» en cada Comunidad Autónoma, y la consiguiente necesidad de que los Estatutos estén sujetos a la Constitución "como garantía de estabilidad y no fricción en la arquitectura juridico-institucional del Estado» están tomadas de la propuesta popular. Se añade a renglón seguido una nueva aportación de la socialista: «Si a esto añadimos su

39 Publicado en el Boletín Oficial de las Cortes Generales, Congreso de los Diputados, X Legislatura, Serie B: Proposiciones de Ley, 14 de julio de 2015: http://www.congreso.es/public oficiales/L10/CONG/BOCG/B/BOCG-10-B-233-1. PDF\#page = 1 
carácter de norma con rango de ley, ha de ser el Tribunal Constitucional quien ostente el monopolio de su control de constitucionalidad».

b) Entrando en materia, el Preámbulo se remite, como hacía la proposición popular, a la estimación contenida en el Informe del Consejo de Estado de 2006 en el sentido de que "podría considerarse la conveniencia de reintroducir el recurso previo de inconstitucionalidad», con el fin de «librarlos de la sospecha de inconstitucionalidad», así como "de la acusación explícita de incurrir en ella». La referencia histórica que sigue, sobre el RPI previsto inicialmente en la LOTC y suprimido por la LO 4/1985 de 7 de junio ( "cuando se encontraban todos —o casi todos- los Estatutos de Autonomía en vigor»), y la necesidad y conveniencia de restablecer el RPI «adaptándolo a la actual configuración del Estado», con el fin de "evitar el cuestionamiento constitucional e institucional y vertebrar con rigor jurídico y cobesión social del Estado», también se encontraban en la propuesta del Grupo popular.

c) Se hace énfasis, «eso sí», en que el RPI se retoma «sólo para los Proyectos de Estatutos de Autonomía y sus propuestas de reforma». Ello se justifica retomando casi literalmente argumentos contenidos en la exposición de motivos de la proposición socialista: «Se evita así el principal reproche que mereció en el pasado esta institución juridica cuando pudo ser utilizada por los grupos minoritarios para paralizar la entrada en vigor de normas legales, de carácter orgánico, aprobadas por las Cortes Generales» ${ }^{40}$.

d) Seguidamente, una nueva aportación de la propuesta socialista cierra la justificación propiamente dicha aludiendo de manera velada al mencionado conflicto de legitimidades: «En definitiva, se hace necesario garantizar el, no siempre fácil, equilibrio entre la especial legitimidad que tienen los Estatutos de Autonomía como norma institucional básica de las Comunidades Autónomas, en cuya aprobación intervienen tanto las Comunidades Autónomas como el Estado y, en ocasiones, el cuerpo electoral mediante referéndum, y el respeto de dicho texto al marco constitucional, construido alrededor de la Constitución como norma fundamental del Estado y de nuestro ordenamiento jurídico» ${ }^{41}$.

e) A continuación, el Preámbulo pasa a precisar el alcance de la reforma. Esta afecta al art. 2 LOTC, "a efectos de incluir entre las funciones del Tribunal Constitucional el control previo de constitucionalidad en los casos previstos en el artículo 79 de

40 Se suaviza así, en cierto modo, el tenor literal de la exposición de motivos socialista, que aludía a la configuración del recurso previo, hasta 1985, como factor distorsionador del sistema de relaciones entre los poderes constitucionales del Estado, entre mayorías y minorías. Las cursivas son siempre nuestras.

${ }^{41}$ Se trata, sin embargo, de una mención más velada a dicho conflicto, pues desaparece la expresión «choque de legitimidades» presente en la exposición de motivos socialista; choque «que implica que el texto aprobado, incluso ratificado por los ciudadanos mediante el correspondiente referéndum, sea declarado inconstitucional años más tarde, con el perjuicio en términos sociales y políticos que ello puede producir», y que se evita reintroduciendo el recurso previo. 
la presente Ley (Proyectos de Estatutos de Autonomía y sus propuestas de reforma)». Se acoge, por tanto, la opción de la proposición popular por someter a control previo tanto los nuevos Estatutos como las reformas de los mismos. La reforma afecta, en segundo lugar, al art. 10 LOTC en el sentido de incluir el RPI entre los asuntos que corresponde conocer al Tribunal en Pleno. Finalmente, se menciona la incorporación de un nuevo Título VI bis (cuya denominación será «Del recurso previo de inconstitucionalidad contra Proyectos de Estatutos de Autonomía y contra Propuestas de Reforma de Estatutos de Autonomía»), incluyendo el nuevo artículo 79 (al que había dejado sin contenido la LO 4/1985 $)^{42}$. Concluye el Preámbulo anticipando de manera resumida la regulación del nuevo RPI.

f) El nuevo art. 79 LOTC consta de nueve párrafos. En el primero de ellos se concretan las normas susceptibles de recurso previo de inconstitucionalidad: «los Proyectos de Estatutos de Autonomía y las propuestas de reforma de los mismos». El párrafo segundo precisa que el texto sobre el que podrá recaer la impugnación será el «definitivo del Proyecto de Estatuto o de la Propuesta de Reforma de un Estatuto, una vez aprobado por las Cortes Generales». Se simplifican así las previsiones contenidas a este respecto en la proposición popular de $2014^{43}$. El párrafo tercero establece que «Están legitimados para interponer el recurso previo de inconstitucionalidad quienes, de acuerdo con la Constitución y con esta Ley Orgánica, están legitimados para interponer recursos de inconstitucionalidad contra Estatutos de Autonomía». En esta remisión a la lista de sujetos legitimados prevista en los arts. 162.1.a) CE y 32 LOTC se produce una coincidencia entre ambas proposiciones de 2014 (si bien la socialista se remite únicamente a la LOTC) y, a su vez, con lo previsto en el art. 79.2 de la LOTC de 1979.

42 Inicialmente, el Título VI de la LOTC llevaba el encabezamiento «Del control previo de inconstitucionalidad», incluyendo en sendos capítulos la declaración sobre la inconstitucionalidad de los tratados internacionales (art. 78) y el RPI contra proyectos de Estatutos de Autonomía y de Leyes Orgánicas (art. 79). La LO 4/1985, de 7 de junio, modifica la rúbrica («De la declaración sobre la constitucionalidad de los tratados internacionales») y reestructura el Título VI al suprimir su división en capítulos, quedando en él únicamente el art. 78, y vacío de contenido el 79. Con la LO 12/2015, se mantiene el Título VI únicamente con el control de los tratados internacionales (art. 78), y se añade un nuevo Título VI bis que da cabida al nuevo art. 79.

43 Se preveía allí la impugnación del texto definitivo «tras su tramitación en ambas Cámaras de las Cortes Generales y una vez que el Congreso se haya pronunciado, en su caso, sobre las enmiendas propuestas por el Senado», en redacción similar a la prevista en el inicial art. 79.1.a) LOTC respecto de la impugnación con carácter previo de las Leyes orgánicas. La redacción del nuevo art. 79.2 LOTC introducido por la LO 12/2015 remite más bien a la proposición socialista de 2014, si bien en esta, como se ha indicado, la impugnación era posible únicamente respecto «del texto definitivo de la propuesta de Reforma de un Estatuto, una vez aprobada por las Cortes Generales», no incluyendo el control de nuevos Estatutos. 
g) Se establece en el nuevo art. 79.4 LOTC un plazo de tres días para la interposición del RPI, contados desde la publicación del texto aprobado en el Boletín Oficial de las Cortes Generales; precisando a continuación que «La interposición del recurso suspenderá automáticamente todos los trámites subsiguientes». Se acoge aquí la redacción más sencilla contenida en la proposición socialista de 2014, ya que, como se recordará, la popular especificaba que la interposición del mismo debía ser anunciada al Presidente del Congreso, así como que, una vez interpuesto el recurso, no procedería la remisión del texto a efectos de su promulgación o publicación en el BOE. Este plazo «extremadamente breve» de tres días se justifica en el Preámbulo "por la naturaleza propia de este recurso», y en él coinciden ambas proposiciones de 2014 y el inicial art. 79.2 LOTC.

b) Los efectos de la interposición del RPI, cuya exposición se iniciaba en el párrafo cuarto (suspensión automática de todos los trámites subsiguientes) se completan en el quinto para el caso concreto de que el nuevo Estatuto o reforma hayan de ser sometidos a referéndum en el territorio de la respectiva Comunidad Autónoma: tal y como se contemplaba en la proposición popular, dicho referéndum «no podrá convocarse hasta que haya resuelto el Tribunal Constitucional y, en su caso, se hayan suprimido o modificado por las Cortes Generales los preceptos declarados inconstitucionales».

i) El párrafo sexto del nuevo art. 79 LOTC recoge, como ya hacían ambas proposiciones de ley, así como la redacción original de la LOTC de 1979, la remisión al capítulo II del Título II, de manera que el RPI no solo coincide con el recurso de inconstitucionalidad en cuanto a la legitimación, sino también en cuanto a la tramitación del procedimiento. Se introduce, eso sí, el plazo para la resolución aportado por la iniciativa socialista: el RPI «deberá ser resuelto por el Tribunal Constitucional en el plazo improrrogable de seis meses desde su interposición. El Tribunal dispondrá lo necesario para dar cumplimiento efectivo a esta previsión, reduciendo los plazos ordinarios y dando en todo caso preferencia a la resolución de estos recursos sobre el resto de asuntos en tramitación». En el Preámbulo de la LO 12/2015 se justifican el plazo y el carácter preferente "para impedir dilaciones indeseables en su resolución». Ambos extremos resultan novedosos con respecto al inicial art. 79 LOTC.

j) Los efectos de la sentencia desestimatoria quedan regulados en el párrafo séptimo del nuevo art. 79 LOTC: «Cuando el pronunciamiento del Tribunal declare la inexistencia de la inconstitucionalidad alegada, seguirán su curso los trámites conducentes a su entrada en vigor, incluido, en su caso, el correspondiente procedimiento de convocatoria y celebración de referéndum». Esta última mención resultaba previsible, teniendo en cuenta que la evitación de una STC sobre un Estatuto ya ratificado en referéndum era una de las claves de la reforma, como hemos ido viendo en estas páginas. La redacción procede de la propuesta socialista (más detallada en 
este punto que la popular, la cual se limitaba a reproducir el párrafo 4.a) del art. 79 en su redacción original de 1979).

k) De los efectos de la sentencia estimatoria se ocupa el nuevo párrafo octavo: «Si, por el contrario, declara la inconstitucionalidad del texto impugnado, deberá concretar los preceptos a los que alcanza, aquellos que por conexión o consecuencia quedan afectados por tal declaración y el precepto o preceptos constitucionales infringidos. En este supuesto, la tramitación no podrá proseguir sin que tales preceptos hayan sido suprimidos o modificados por las Cortes Generales». Se acoge aquí la redacción de la propuesta popular, ya que la socialista incluía una redacción prácticamente similar al originario art. 79.4.b) LOTC (respecto del cual únicamente precisa el «órgano competente» mencionando de modo expreso a las Cortes Generales). La LO 12/2015 incorpora, por tanto, la posibilidad de que la declaración de inconstitucionalidad vaya más allá de los preceptos impugnados, alcanzando a aquellos «que por conexión o consecuencia quedan afectados por tal declaración». Se trata de un nuevo paralelismo con los procedimientos de inconstitucionalidad a posteriori, ya que esa posibilidad se recoge en términos similares en el art. 39.1 LOTC.

l) El noveno y último párrafo del art. 79 LOTC ex LO 12/2015, retoma la posibilidad (prevista en el precepto de 1979, así como en la proposición popular) de que el control del mismo texto sobre el que en su momento no se apreció inconstitucionalidad vía RPI, pueda ser promovido de nuevo con carácter sucesivo: «El pronunciamiento en el recurso previo no prejuzga la decisión del Tribunal en los recursos o cuestiones de inconstitucionalidad que pudieren interponerse tras la entrada en vigor con fuerza de ley del texto impugnado en la vía previa». Se opta, pues, por una solución contraria a la prevista en el art. 38.2 LOTC, que además, como veremos, hace perder al RPI buena parte de su utilidad.

m) Desaparece en la LO 12/2015 la Disposición transitoria según la cual la misma únicamente sería aplicable a los Estatutos de Autonomía que iniciasen su tramitación parlamentaria con posterioridad a la entrada en vigor de la ley. Esta disposición resultaba ya innecesaria, toda vez que en 2015 la reforma del Estatuto de Castilla-La Mancha (LO 2/2014 de 21 de mayo) estaba tramitada, en vigor, y posteriormente avalada por el Tribunal Constitucional (STC 197/2014, de 4 de diciembre). Se mantiene, eso sí, la Disposición final que preveía la entrada en vigor de la LO 12/2015 al día siguiente de su publicación en el BOE (publicación que tuvo lugar, como se ha indicado, el 23 de septiembre de 2015).

Se comprueba así, en suma, el carácter pactado de la reforma, que recoge lo más aprovechable de las iniciativas legislativas socialista y popular de 2014, siguiendo a su vez muy de cerca (tal y como había hecho, sobre todo, la propuesta popular) la redacción original del art. 79 LOTC suprimido en 1985. 


\section{LA LEY ORGÁNICA 12/2015: ANÁLISIS, VALORACIÓN Y PROPUESTAS}

El enfoque eminentemente descriptivo utilizado en el apartado anterior para aproximarnos al contenido de la LO 12/2015, ha de completarse ahora con el análisis crítico, adoptando una mirada más valorativa, que nos lleve a situar la lupa en, al menos, algunos de los problemas que plantea la recuperación del RPI, tanto por el contenido de la reforma que reintroduce el art. 79 LOTC, como por todo lo que en ella se echa de menos.

A propósito del recurso previo se ha escrito que, si bien "puede, como es obvio, evitar los perjuicios jurídicos y políticos ocasionados por la entrada en vigor y consiguiente aplicación de una Ley luego declarada inconstitucional», «parece acertada una configuración restrictiva» del mismo, que se limite «a las propuestas de reforma estatutaria y no, en general, a la aprobación o modificación de cualquier Ley Orgánica», y ello «dada la presunción de constitucionalidad de las Leyes aprobadas por los Parlamentos democráticos», afirmada en la citada STC 66/1985, de 23 de mayo (dictada en relación con la LO 4/1985, que suprimía el recurso previo ${ }^{44}$. Claro está que la propia existencia del control de constitucionalidad (independientemente de que se ejerza a priori o a posteriori) significa que esa presunción se puede romper. La actuación del legislador, como la de cualquier otro poder público, es susceptible potencialmente de vulnerar o contradecir la Constitución. Cierto es que existe una presunción a favor de la adecuación de las leyes a la Constitución; pero, ¿por qué es mejor romper esa presunción cuando la ley ya está vigente que cuando todavía no lo está? Lo que hay que presumir adecuado a la voluntad popular es la Constitución: lo que va contra ella, se opone a la voluntad popular aunque proceda del Parlamento. El control previo implica que la presunción se romperá, en su caso, antes de que la norma impugnada entre en vigor; lo cual, precisamente, evita los inconvenientes de la declaración de inconstitucionalidad a posterior ${ }^{45}$. Desde esta premisa resulta más fácil valorar lo que contiene, y lo que no contiene, la reforma de la LOTC que recupera el RPI para «los Proyectos de Ley Orgánica de Estatuto de Autonomía o de su modificación».

${ }^{44}$ M. A. Presno Linera, «El regreso del recurso previo de inconstitucionalidad», cit.

45 Para I. ViIllaverde Menéndez, «Esta resistencia a dotar al TC de instrumentos como el recurso previo tiene que ver, en definitiva, con una cierta duda larvada aún sobre la legitimidad democrática de la jurisdicción constitucional y su percepción como un cuerpo extraño dentro de la democracia representativa» («El control previo de constitucionalidad de las normas con rango de ley. Crónica de un escéptico», cit., pág. 40). 
1) La LO 12/2015 modifica los artículos 2 y 10 LOTC, como si se tratara de introducir una nueva competencia del Tribunal Constitucional. Así se hace constar expresamente en el Preámbulo: «Se modifica el artículo 2, a efectos de incluir entre las funciones del Tribunal Constitucional el control previo de constitucionalidad en los casos previstos en el artículo 79 de la presente Ley». Se introduce en tal sentido un nuevo epígrafe $e$ ) bis en el art. 2.1 LOTC ( $D$ Del control previo de inconstitucionalidad en el supuesto previsto en el artículo setenta y nueve de la presente Ley»). Asimismo, se añade un apartado $d$ ) bis al art. 10 para incluir, entre los asuntos de que conoce el Tribunal en Pleno, «los recursos previos de inconstitucionalidad contra Proyectos de Estatutos de Autonomía y contra propuestas de Reforma de los Estatutos de Autonomía».

El recurso previo no es una función del Tribunal Constitucional distinta del recurso de inconstitucionalidad (con el que comparte legitimación y tramitación según hemos visto), sino que uno y otro son modalidades distintas de ejercicio de una misma función —el control de constitucionalidad — estando la principal diferencia entre ambas en el momento de ejercerse el control y, en función de ello, en los efectos de la decisión o, dicho de otro modo, en el modo de lograr el objetivo común a ambas modalidades: la depuración del ordenamiento jurídico. Si en el recurso a posteriori la sentencia estimatoria trae consigo la desaparición del ordenamiento de la norma declarada inconstitucional (y, lógicamente, la imposibilidad de que vuelva a ser aplicada), en el recurso previo la sentencia estimatoria conllevará que la norma declarada inconstitucional no podrá llegar a entrar en vigor. El resultado es, desde el punto de vista de la defensa del orden constitucional, el mismo: la imposibilidad de producir efectos, si bien se produce - y esta es la diferencia- en un caso sobre una norma que ya había producido efectos (o estaba en condiciones de producirlos) y, en otro caso, sobre una norma que aún no podía producirlos. Los efectos generales de la sentencia implican que la norma no podrá ser aplicada en ningún caso, y en la obligación dirigida al legislador de adecuar a la Constitución el texto de la misma. La actividad de control abstracto y objetivo es la misma, de manera que no tiene por qué cambiar la forma de abordar los asuntos por parte del Tribunal Constitucional, su análisis y su respuesta. No estamos, en suma, ante una nueva competencia del Tribunal Constitucional, sino ante una nueva modalidad de control de constitucionalidad, conforme con los párrafos 1.a) y 1.d) del art. $161 \mathrm{CE}$, epígrafe éste último que atribuye al Tribunal el conocimiento de «las demás materias que le atribuyan la Constitución o las leyes orgánicas». La inclusión del RPI en la LOTC supuso en 1979 y supone ahora una novedad menor de lo autorizado por el 161.1.d): si éste permite lo más (atribuir el conocimiento de nuevas materias —lo 
que supone, en definitiva, nuevas competencias-), permite también lo menos (introducir una nueva técnica para llevar a cabo una misma competencia) ${ }^{46}$.

El art. 2 LOTC no dedica epígrafes diferentes al recurso y a la cuestión de inconstitucionalidad al enumerar los casos de los que conoce el Tribunal, porque ambas son modalidades de ejercicio del control de constitucionalidad. La referencia al recurso previo bien podría haberse incluido en el epígrafe 1.a) de dicho artículo ${ }^{47}$.

2) Al referirse a las normas sometidas a control, se insiste en la denominación «Proyectos de Ley Orgánica de Estatuto de Autonomía»y «Proyectos de Estatutos de Autonomía», e introduce la de "propuestas de reforma» de los mismos. Así sucede conforme a la redacción dada a los párrafos 1, 2 y 5 del art. 79, además de en el Preámbulo y en propio encabezamiento de la LO 12/2015.

El RPI no se ejerce sobre proyectos ni propuestas, sino sobre el «texto definitivo» (así se reconoce en el propio párrafo segundo) del nuevo Estatuto o de su reforma. Es obvio que el control de constitucionalidad no puede ni debe interferir en el debate parlamentario, ni tendría sentido antes de que las Cámaras hubieran llegado a una versión final del texto normativo (así lo veíamos ya en relación con el ATC 85/2006, de 15 de marzo). Ahora bien: tanto el control sucesivo (recurso o cuestión de inconstitucionalidad) como el previo, se ejercen a posteriori respecto de la acción del legislador. Tanto en el RPI previsto en 1979 como en el reintroducido por la LO 12/2015, el legislador ya ha terminado su labor: se trata del texto definitivo, faltando solo los pasos subsiguientes que han de posibilitar, en su caso, la entrada en vigor de la disposición impugnada. Sanción, promulgación y publicación —arts. 62.a) y 91 CE_ son actos que quedan fuera del procedimiento de aprobación parlamentaria de la ley: son requisitos para que la norma pueda alcanzar vigencia, pero no para su existencia como tal ${ }^{48}$. En suma, lo que se ha

46 Como apunta I. Villaverde Menéndez, («El control previo de constitucionalidad de las normas con rango de ley. Crónica de un escéptico», cit., págs. 29-30), en las SSTC que resolvieron los recursos previos apenas se contienen reflexiones del Tribunal sobre el sentido y el significado de este procedimiento. «Formalmente, si se leen las seis sentencias dictadas por el TC en este tipo de recurso, no existen diferencias con los recursos inconstitucionales resueltos coetáneamente. La forma de abordar los asuntos, su análisis y su respuesta no difieren de un caso y otro».

${ }^{47}$ La redacción, en ese supuesto, habría sido similar a la siguiente: «Del recurso y de la cuestión de inconstitucionalidad contra leyes, disposiciones normativas o actos con fuerza de ley, así como del recurso previo de inconstitucionalidad en el supuesto previsto en el artículo setenta y nueve de la presente ley». En el artículo 10 LOTC, que sí dedica apartados diferentes al recurso y a la cuestión de inconstitucionalidad, estableciendo en ambos casos excepciones a su conocimiento por parte del Pleno, sí estaría justificado por razones sistemáticas dedicar un epígrafe específico al RPI del art. 79, para subrayar que debe ser resuelto por el Pleno en todo caso.

48 Existen, incluso, normas que son objeto de control y que, sin embargo, no están sujetas a sanción y/o promulgación. Así, las leyes autonómicas son promulgadas pero no sancionadas; los 
escrito en relación con el RPI de 1979 se puede aplicar también al actual: este recurso afecta «a una ley ya perfecta, a pesar de que el citado artículo se refiere al proyecto de Estatuto [...] como si el procedimiento legislativo en las Cámaras no hubiese concluido ya en ese momento, realizando así una catalogación errónea, que podría dar a entender que el texto en cuestión no estaba perfeccionado [...]. Nótese que el mismo precepto de la LOTC reitera que el objeto del recurso previo ha de ser el texto definitivo del Estatuto de Autonomía [...] revelando así que no es propiamente un proyecto legislativo lo que se impugna, sino una ley, privada, eso sí, de los trámites de sanción-promulgación real y de publicación en el BOE y de la consiguiente fuerza de obligar» ${ }^{49}$.

3) Están legitimados para interponer el RPI quienes lo están para interponer recursos de inconstitucionalidad contra Estatutos de Autonomía.

Este aspecto de la legitimación enlaza a su vez con el momento de promover el control y con los efectos de la interposición del recurso $0^{50}$. Al respecto cabe la opción acogida por la LOTC tanto en 1979 como en la actualidad (que el recurso se promueva por parte de cualquiera de los sujetos legitimados una vez que el texto esté definitivamente concluido), o bien la de dotarlo de un carácter preceptivo u obligatorio (a la manera del clásico modelo francés respecto de las leyes orgánicas), evitándose así posibles maniobras políticas en relación con la impugnación o no de la norma así como problemas atinentes a la legitimación). A esto último podría objetarse que entonces no estaríamos propiamente ante un recurso; pero ello no supondría la negación de su carácter jurisdiccional. Y en todo caso, el control previo con carácter preceptivo supondría indudables ventajas: por una parte se evitaría que un

decretos legislativos no se sancionan ni promulgan, sino que se expiden por el Rey con el refrendo del Presidente del Gobierno y se publican en el BOE (art. 62.f CE); y lo mismo ocurre con los decretos-leyes. Es cierto que los Estatutos de Autonomía y las reformas de los mismos sí están sujetos a sanción y promulgación al ser aprobados por Ley orgánica (art. 81.1 CE); pero lo que aquí queremos destacar es que ni la sanción ni la promulgación son requisitos indispensables para que una norma pueda ser objeto de control de constitucionalidad. Tampoco la publicación, que es únicamente un requisito para la eficacia y que, además, en las normas que sí se sancionan y/o promulgan, tiene lugar, lógicamente, con posterioridad a la sanción y promulgación.

49 F. Santaolalla López, «Problemas del recurso previo de inconstitucionalidad y adición sobre la LOAPA», cit., págs. 177-178. Estas mismas consideraciones se recogían en la Exposición de motivos de la propia LO 4/1985, que suprimió el RPI, en la cual se habla de "proyectos que, por haber sido aprobados por las Cámaras, han dejado de serlo para transformarse en Leyes, si bien carentes todavía de sanción».

${ }^{50}$ En concreto, tiene que ver con el plazo de impugnación de tres días desde la publicación del texto definitivo en el BOCG, previsto en el actual art. 79.4 LOTC, que en la versión original de 1979 empezaba a contar «desde que el texto definitivo del proyecto recurrible estuviere concluido». Además, como ya se ha indicado, según el mismo 79.4 en su actual redacción, «La interposición del recurso suspenderá automáticamente todos los trámites subsiguientes». 
amplio consenso político permitiera la entrada en vigor de normas inconstitucionales cuya declaración de inconstitucionalidad a posteriori sería especialmente traumática (consenso no equivale a conformidad con la Constitución). Por otra, dado que el control previo supone la suspensión de la entrada en vigor de la norma controlada (y, en su caso, la celebración de referéndum), es preferible que dicho control se lleve a cabo cuanto antes, sin tener que esperar a que transcurra un plazo para la impugnación. Se eliminaría igualmente el problema de determinar si la suspensión de la entrada en vigor debe afectar a toda la disposición normativa o únicamente a los preceptos impugnados, pues el Tribunal Constitucional controlaría obligatoriamente la constitucionalidad de toda ella.

En suma, y como acertadamente se ha escrito, «si lo que se pretende es evitar un "choque de legitimidades" y los "graves perjuicios" que puede ocasionar una tardía sentencia del TC en vía del recurso sucesivo, el control previo debería ser obligatorio y de oficio. Otorgar legitimidades activas a sujetos o a órganos siempre conlleva poner a disposición de la voluntad de la minoría parlamentaria derrotada, o de un Gobierno de la Nación opuesto al proyecto de reforma estatutaria, o frustrado por no haber podido controlar el proceso hasta su final o el contenido del nuevo EA, el arma política de torcer el acuerdo mayoritario; aunque sea por un tiempo» ${ }^{51}$.

4) La LO 12/2015 establece un "plazo improrrogable de seis meses desde su interposición» para que el RPI sea resuelto por el TC (art. 79.6 LOTC). Con el fin de dar efectivo cumplimiento a esta previsión, el Tribunal debe disponer lo necesario, "reduciendo los plazos ordinarios y dando en todo caso preferencia a la resolución de estos recursos sobre el resto de asuntos en tramitación».

Sin duda, es un acierto el establecimiento de un breve período de tiempo para la resolución del RPI, con el fin de intentar evitar tentaciones obstruccionistas y dilaciones indeseables; asimismo, el cumplimiento de ese plazo es imprescindible para un adecuado funcionamiento del recurso previo. Lo que ocurre es que la previsión de este lapso de seis meses genera una incongruencia sistemática dentro de la LOTC, ya que el procedimiento urgente y prioritario que pretende ser el RPI cuenta para su resolución con un plazo mayor que el

51 I. Villaverde MenéndeZ, «El control previo de constitucionalidad de las normas con rango de ley. Crónica de un escéptico», cit., pág. 31. En pág. 40 vuelve sobre esta idea: «que el control se inste de oficio es la solución más acertada» para evitar el «uso filibustero del control previo».

Esta solución es compatible con la propuesta de P. CruZ VILLALón en 2006 («El control previo, a los veinte años de su supresión», cit., pág. 289): «El momento del control previo de las reformas de los Estatutos debiera ser una vez que el texto está fijado por parte de ambos parlamentos, pero en todo caso de forma previa a la ratificación por vía de referéndum». 
previsto en el art. 34.2 para el recurso de inconstitucionalidad ${ }^{52}$. En este sentido, la consideración de los seis meses como un plazo breve para resolver el RPI a partir de su interposición, únicamente puede entenderse como un reconocimiento, por parte del legislador, del patente incumplimiento del plazo previsto para el control a posteriori.

5) Tras la entrada en vigor del texto impugnado en la vía previa, éste puede ser objeto de recurso o cuestión de inconstitucionalidad. En ese caso, el pronunciamiento en el recurso previo no prejuzga la decisión del Tribunal.

Esta previsión resulta criticable al venir a restar utilidad al control previo, ya que no supone la entrada en vigor del Estatuto de Autonomía, o de su reforma, con plenas garantías de constitucionalidad ${ }^{53}$. Sin embargo, a efectos prácticos, el control previo tampoco tendría utilidad alguna si el legislador, al reelaborar la norma, no estuviera sometido a ningún control (si bien, en ese caso, ya estaríamos hablando de un texto diferente, el reelaborado, y no del sometido a control previo). A la vista de todo ello, quizá habría sido adecuado prever la imposibilidad de que los preceptos impugnados pudieran ser sometidos posteriormente a nuevo control de constitucionalidad en el caso de que, en la vía previa, bubieran sido declarados conformes a la Constitución. La posibilidad de control sucesivo, lógicamente, podría haber quedado abierta para los preceptos no impugnados en la vía previa. En los supuestos en los que el Tribunal declarara la inconstitucionalidad en la vía previa, podría haberse previsto la posibilidad de un control a posteriori (o, incluso, la posibilidad de un nuevo recurso previo) sobre el texto reelaborado por las Cortes Generales, para evitar que el legislador volviera a optar por la solución que había sido considerada contraria a la Constitución en la vía previa. En definitiva, al menos desde un punto de vista meramente técnico, los preceptos impugnados en el RPI, y que el Tribunal hubiera declarado conformes a la Constitución, deberían ser incontesta-

52 «La personación y la formulación de alegaciones deberán hacerse en el plazo de quince días, transcurrido el cual el Tribunal dictará sentencia en el de diez, salvo que, mediante resolución motivada, el propio Tribunal estime necesario un plazo más amplio que, en ningún caso, podrá exceder de 30 días». Para la cuestión de inconstitucionalidad, el art. 37.3 LOTC prevé, transcurridos los quince días para formular alegaciones, un plazo de quince días para dictar sentencia, que no podrá exceder el de treinta días si ello se estima necesario mediante resolución motivada.

53 Como acertadamente escribe O. Salazar Benítez, la previsión contenida en la regulación inicial de la LOTC en el sentido de que el pronunciamiento en el recurso previo no prejuzgaría la decisión del Tribunal en los recursos a posteriori que pudieran interponerse, «no tiene mucho sentido ya que supone abrir la posibilidad de establecer un doble proceso sobre un mismo objeto. Es decir, no tendría mucho sentido que volviera a 'reabrirse' el debate sobre un texto que ya se habría depurado de sus posibles infracciones constitucionales» ( «Sobre la inconveniencia de introducir el recurso previo de inconstitucionalidad en los procedimientos de reforma estatutaria», cit., pág. 472 . 
bles en la vía sucesiva, respetando así la fuerza de cosa juzgada de las sentencias del Tribunal (art. 164.1 CE). Es más, si consideramos más adecuado que el control previo tenga carácter preceptivo y obligatorio según acabamos de indicar, una vez que el legislador opte por la reelaboración de los preceptos declarados inconstitucionales, los preceptos modificados, así como los conexos, deberían ser objeto de nuevo control preventivo obligatorio, que garantice que la norma que finalmente entra en vigor sea conforme con la Constitución ${ }^{54}$.

6) Entrando ya en lo que se echa de menos en la reforma de la LOTC, cabe mencionar en primer lugar la falta de previsión para el caso de que transcurran los seis meses sin que el Tribunal haya dictado sentencia, y tampoco se regulan las consecuencias de que las Cortes no se atengan al fallo, y envíen a sanción y promulgación el texto sin modificar o solo modificado parcialmente; faltan, igualmente, las reglas sobre la devolución a las Cortes del texto declarado inconstitucional, y sobre la tramitación legislativa del fallo de inconstitucionalidad ${ }^{55}$.

Para la primera de las cuestiones señaladas, seguramente debería alcanzarse una solución con carácter general, ya que tampoco hay previsión alguna en la LOTC (arts. 34.2, 37.3, 52.3, etc.) para el incumplimiento del plazo que el TC tiene marcado para dictar sentencia en los demás procedimientos constitucionales. La solución a las otras carencias apuntadas podría venir actualmente de la mano de la LO 15/2015, de 16 de octubre (BOE 17 de octubre), que reforma la LOTC en lo relativo a la ejecución de las resoluciones del Tribunal Constitucional como garantía del Estado de Derecho ${ }^{56}$. En cuanto a la supresión o modificación por

54 A. J. Gómez Montoro ( «El control previo de constitucionalidad de proyectos de Estatutos de Autonomía y demás Leyes Orgánicas», cit., pág. 162), proponía una distinción a los efectos de mejorar la regulación del RPI: si se optara por la publicación del texto sin los preceptos declarados inconstitucionales, debería ser reconocida la fuerza de cosa juzgada de la sentencia recaída en el recurso previo. Por el contrario, si se introdujeran modificaciones en el mismo, debería ser posible ulterior recurso, que podría haberse planteado, incluso, en la vía previa.

55 Estas carencias, apuntadas por I. Villaverde MenÉNDEZ («El control previo de constitucionalidad de las normas con rango de ley. Crónica de un escéptico», cit., pág. 31) en relación con las proposiciones de Ley orgánica de 2014, se observan también en el texto definitivo de la LO 12/2015.

56 Como es sabido, se da aquí nueva redacción, entre otros, al art. 92 LOTC, sobre la base de que «El Tribunal Constitucional velará por el cumplimiento efectivo de sus resoluciones». A este respecto, el Tribunal, de oficio o a instancia de parte, requerirá a quien corresponda llevar a cabo el cumplimiento de una resolución dictada en el ejercicio de su jurisdicción, para que informe al respecto en el plazo que se fije. Recibido el informe o transcurrido el plazo, si el TC constata el incumplimiento total o parcial de su resolución, podrá adoptar cualquiera de las medidas previstas en el art. 92.4 LOTC (multa coercitiva, suspensión en sus funciones de las autoridades responsables del incumplimiento, ejecución sustitutoria de la resolución, o deducir el testimonio de los particulares para exigir la responsabilidad penal que pudiera corresponder). 
parte de las Cortes de los preceptos declarados inconstitucionales, las previsiones normativas específicas que pudieran ser necesarias para su tramitación, encontrarían su ubicación más adecuada en los Reglamentos de las Cámaras.

7) La LO 12/2015 señala, como objeto del RPI, únicamente los Estatutos de Autonomía y las reformas de los mismos. A diferencia de la regulación de 1979, no se contempla para el resto de leyes orgánicas.

Consideramos que el principal argumento a favor de la extensión del control previo a las leyes orgánicas es el de la difícil o imposible reparación de los efectos desplegados por una ley declarada inconstitucional, lo cual puede ser especialmente delicado en relación con materias tan relevantes y sensibles como las que la Constitución reserva a ley orgánica en el artículo 81. Por mucho que se pueda objetar que la mejor manera de detectar la posible inconstitucionalidad de una ley es a través de su aplicación, lo más habitual es que la inconstitucionalidad se manifieste sin necesidad de esperar a los efectos de su puesta en práctica; y el precio que supondría la espera podría ser demasiado alto. Además, la interposición del recurso de inconstitucionalidad a posteriori obedece a un plazo marcado en la ley (art. 33 LOTC), independientemente de que ésta se haya aplicado o no ${ }^{57}$.

8) Tampoco está previsto en la LO 12/2015 (como no lo estaba en la redacción original de la LO 2/1979) el recurso previo para las reformas constitucionales ni para otras normas respecto de las cuales podría contemplarse.

Se ha escrito al respecto que «el control previo debería instituirse quizá como una suerte de procedimiento de obligada observancia para el caso de normas como los EEAA, leyes orgánicas o de reforma constitucional» ${ }^{58}$. Se apunta asimismo que el problema planteado por el eventual control sucesivo de una reforma constitucional vendría sobre todo «de la dificultad lógica, en una concepción extendida en España, de contrastar con la Constitución lo que es ya Constitución, lo que ha pasado a formar parte de la Constitución» ${ }^{59}$.

57 Desde otro punto de vista, pero a propósito de este dato, P. Cruz Villalón ( «El control previo de constitucionalidad», cit., pág. 18) afirmaba en 1981 el «carácter superfluo» del RPI, considerándolo además innecesario porque el recurso de inconstitucionalidad a posteriori «funciona prácticamente, materialmente, como un recurso previo. El plazo para entablarlo es, como se sabe, el de tres meses, a partir de la publicación de la norma, publicación que, como también se sabe, no coincide ordinariamente con la entrada en vigor, que nada impide que pueda ser pospuesta más allá de los tres meses. Con independencia de ello, los efectos de la entrada en vigor de la norma suelen tardar bastante más de tres meses en dejarse sentir». En la actualidad el plazo para interponer el recurso se amplía a nueve meses, siempre que se cumplan los requisitos establecidos en el art. 33.2 LOTC según la redacción dada por la LO 1/2000, de 7 de enero (BOE 10 enero 2000).

58 I. Villaverde MenÉndeZ, «El control previo de constitucionalidad de las normas con rango de ley. Crónica de un escéptico», cit., pág. 31.

59 P. Cruz Villalón, «El control previo, a los veinte años de su supresión», cit., pág. 289. 
En relación con un hipotético control previo de las reformas constitucionales, no resulta posible entrar aquí en el complejo problema de si únicamente cabría, en su caso, respecto de su adecuación formal al procedimiento constitucionalmente previsto (por ejemplo, si se siguiera el procedimiento del artículo 167 para reformar un precepto sujeto al más agravado procedimiento del artículo 168), lo cual parece en principio más adecuado, o si cabría también un control material que tratara de determinar si una reforma constitucional ha traspasado los límites implícitos al poder de revisión ${ }^{60}$. Independientemente de que se las denomine leyes de reforma constitucional o reformas constitucionales (denominación que consideramos más exacta), lo cierto es que «una vez aprobadas no son leyes, sino Constitución y, por tanto, insusceptibles de control de constitucionalidad. Estamos, pues, ante una laguna importante, que debería ser colmada mediante el establecimiento de un control previo de los proyectos de reforma constitucional» ${ }^{61}$. En suma, «tal instituto parece indicado para los proyectos y proposiciones de reforma constitucional. Seguramente habría de ser una garantía para no ser utilizada sino en caso extremo, en un indeseable supuesto de disenso insalvable, lo que siempre sería grave para el país» ${ }^{62}$. Lógicamente, en la línea de lo que en estas páginas venimos manteniendo, el hipotético control debería ejercerse sobre el texto ya concluido, con anterioridad a su presentación para sanción y promulgación regia y, en su caso, con anterioridad a la celebración de referéndum.

Por otra parte, el control previo podría extenderse también a los reglamentos parlamentarios (por la especial trascendencia de su regulación en vista de que su inconstitucionalidad podría determinar a su vez la inconstitucionalidad formal de las normas que se elaboren en aplicación de los mismos) y a otras cuya decla-

${ }^{60}$ Dos aportaciones específicas sobre el control de constitucionalidad de las reformas constitucionales son las de R. Rodríguez GaONA, El control constitucional de la reforma a la Constitución, Madrid, Dykinson, 2006, y D. García Belaúnde, «Sobre el control de la reforma constitucional (con especial referencia a la experiencia jurídica peruana)», Revista de Derecho Político, n. ${ }^{\circ}$ 66, Madrid, UNED, 2006, págs. 477-500. Véase también el magnífico estudio comparativo que sobre el tema lleva a cabo J. BRAGE CAMAZANO, La acción abstracta de inconstitucionalidad, cit., págs. 256-274 (y de manera específica las págs. 267-268), donde plantea la posibilidad de control (formal) de las reformas constitucionales «para evitar un Caballo de Troya (in)constitucional».

${ }^{61}$ A. Torres Del Moral, Principios de Derecho Constitucional Español. Tomo II: Instituciones Políticas, Madrid, Servicio de Publicaciones de la Facultad de Derecho de la Universidad Complutense, 5. a ed., 2004, pág. 387.

62 A. Torres Del Moral, Principios de Derecho Constitucional Español. Tomo I: Sistema de fuentes. Sistema de los derechos, Madrid, Servicio de Publicaciones de la Facultad de Derecho de la Universidad Complutense, 6. ${ }^{a}$ ed., 2010, pág. 293. 
ración de inconstitucionalidad a posteriori pudiera producir efectos especialmente traumáticos (como podrían ser las leyes tributarias, «leyes tributarias sustantivas», como las llama el artículo 134.7 CE).

Claro está que las propuestas aquí apuntadas, y especialmente la de establecer el RPI con carácter preceptivo y obligatorio, no pueden contemplarse (y valorarse su viabilidad y/o conveniencia) aisladamente, sino en el contexto de las reformas legales, e incluso constitucionales, que probablemente requerirían. Ciertamente, de lo escrito hasta aquí se deduce que la ubicación adecuada para el recurso previo es la LOTC, no siendo necesaria su mención expresa en la Constitución, pues como hemos visto tiene cabida en ella. Sin embargo, y aunque no sea en puridad imprescindible la reforma constitucional, la plena adecuación técnica del RPI a la Constitución, así como la correcta articulación entre un eventual control previo obligatorio y el control sucesivo, conllevaría la necesidad de modificar algunos preceptos más en la LOTC, así como en la propia Constitución. A este respecto, habrá que apresurarse a señalar que cualquier propuesta de lege ferenda relativa a nuevas reformas de la LOTC y (más aún en el contexto actual) de la Constitución, debe realizarse exclusivamente desde una perspectiva técnico-jurídica, y a la luz de los problemas planteados por la anterior regulación, y teniendo también en cuenta la experiencia aportada por otros ordenamientos $^{63}$.

${ }^{63}$ Sin perjuicio de que el tema requiera una reflexión más extensa, y a título meramente ejemplificativo, consideramos que la LOTC debería incluir el objeto del control previo (que podría estar referido al control formal de las reformas constitucionales, los Estatutos de Autonomía y sus reformas, las demás leyes orgánicas previstas en la Constitución y, en su caso, los Reglamentos de las Cámaras y las leyes tributarias). Debería aclararse que el texto sometido a control no podrá ser presentado al Rey para sanción y promulgación mientras el Tribunal no haya dictado sentencia, y especificarse los efectos de ésta, distinguiendo en función de que apreciara o no la inconstitucionalidad, en los términos indicados.

Asimismo, convendría retocar la regulación del control previo de tratados en la LOTC, estableciéndolo como obligatorio al menos para los previstos en los artículos 93 y $94.1 \mathrm{CE}$ (en el caso de los del 94.2, la declaración obligatoria por parte del Tribunal podría producirse únicamente a requerimiento del Gobierno o cualquiera de las Cámaras). Convendría insistir en el carácter vinculante de la resolución del Tribunal, y podría añadirse que respecto del Tratado declarado conforme a la Constitución, una vez que el consentimiento del Estado se haya prestado, únicamente sería posible el control de constitucionalidad en el caso de que la Constitución sea reformada y pudieran surgir dudas de adecuación entre el Tratado y el nuevo tenor constitucional.

Por lo que se refiere a reformas constitucionales, el artículo 161.1.a) podría quedar redactado en los siguientes términos: «Del control de constitucionalidad, con carácter previo o sucesivo según los casos, contra leyes y disposiciones normativas con fuerza de ley, así como del control previo de constitucionalidad formal de las reformas constitucionales, con anterioridad, en su caso, a la celebración de referéndum». El artículo 91 pasaría a quedar redactado: «El Rey sancionará, en el 


\section{CONCLUSIONES}

Primera. Para que el control de constitucionalidad sea garantía y no obstáculo, es imprescindible que el Tribunal resuelva en un plazo razonable, lo cual, según nos enseña la experiencia española, depende de multitud de factores, y no solo del carácter preventivo o sucesivo del mismo. Cierto es que el control previo puede ser ejercido con finalidad obstruccionista. Ahora bien: ni que decir tiene que la oposición se vería (y, en el caso del RPI español hasta su supresión hasta 1985, se habría visto) en buena medida disuadida de utilizarlo con este fin si el Tribunal Constitucional dictara o hubiera dictado sus resoluciones con la celeridad legalmente prevista. Lo que se pretende con el control previo, al igual que con el sucesivo, es impedir que la mayoría utilice su fuerza numérica para vulnerar la Constitución, o que tales vulneraciones, conscientes o inconscientes se perpetúen por no llegar a ser enjuiciada por el Tribunal la norma contraria a la Constitución. Aceptar la Justicia constitucional implica asumir que una ley o un Estatuto de Autonomía pueden vulnerar la Constitución, y la posibilidad de acceso al Tribunal Constitucional implica una garantía de cara a la depuración del Ordenamiento jurídico.

Segunda. El otro gran motivo por el que el control previo de constitucionalidad genera críticas y objeciones es el supuesto mayor riesgo de politización de la justicia constitucional. Cabría preguntarse si ese peligro es realmente exclusivo del control a priori, o puede ser afirmado también del control sucesivo. La supresión en 1985 del RPI no evitó que al Tribunal Constitucional siguieran yendo a parar los asuntos más espinosos y problemáticos de la contienda política. Si los riesgos de politización y de judicialización de la vida política existen, y de ello no parece caber duda, existirán con control previo o sin él. ¿No es utilización o instrumentalización política de un Tribunal Constitucional el que un gobierno, pongamos por caso, con tal de llevarse bien con tal o cual fuerza política o Comunidad Autónoma, retire recursos o conflictos interpuestos por gobiernos anteriores? Por lo demás, también alrededor de la tramitación de un recurso de

\footnotetext{
plazo de quince días a partir del día en que le sean presentadas, las leyes...». El artículo 167.3 pasaría a decir: «...dentro de los quince días siguientes a la decisión favorable del Tribunal Constitucional...». Por último, el artículo 168.3 quedaría redactado: «Aprobada la reforma por las Cortes Generales, y una vez que el Tribunal Constitucional se haya pronunciado favorablemente sobre la misma, será sometida a referéndum para su ratificación». En cuanto al control previo de Tratados, coherentemente con lo recién indicado, el artículo 95.2 quedaría: «El Tribunal Constitucional declarará si existe o no esa contradicción. Respecto de los tratados mencionados en el artículo 94.2, esta declaración sólo se producirá si el Tribunal Constitucional es requerido por el Gobierno o por cualquiera de las Cámaras».
} 
inconstitucionalidad pueden darse circunstancias poco ejemplares o edificantes $^{64}$. ¿Debe suprimirse por ello el recurso de inconstitucionalidad? ¿Por qué no aprovechar, con una regulación técnicamente bien elaborada y articulada con el control a posteriori, las ventajas del control preventivo? ${ }^{65}$ El que el Tribunal corrija al legislador no es exactamente un peligro o una tentación en la que deba evitar caer; más bien, la depuración del ordenamiento jurídico declarando inconstitucionales, y por tanto inaplicables, los actos del legislador que se opongan a la Constitución, es, precisamente, la función del Tribunal Constitucional. El que lo haga a priori o a posteriori comportará ventajas o inconvenientes determinados, pero no encontramos argumentos definitivos que muevan a pensar que la actividad de reconducir a la conformidad con la Constitución los actos del legislador sea distinta en intensidad en un supuesto que en otro. Una eventual extralimitación por parte del Tribunal no es tanto un riesgo que pueda detectarse solo en el control previo, sino un problema a tratar en función de cada ordenamiento en concreto, puesto en el contexto marcado por muy diversas circunstancias y variables. Ni siquiera la más perfecta regulación puede

64 «Recusación de magistrados, demora de cuatro años en la resolución, un Tribunal partido en dos mitades prácticamente», son las que apunta J. M. CASTEllà ANDREU («Tribunal Constitucional y proceso secesionista catalán: respuestas jurídico-constitucionales a un conflicto políticoconstitucional», cit., pág. 566) en relación con la tramitación del recurso sobre la reforma del Estatuto catalán, que, como hemos visto, de alguna manera ha desempeñado el papel de catalizador del debate en torno a la recuperación del recurso previo.

65 S. MuÑoz MaCHAdo (Informe sobre España, cit., págs. 209 y ss.) se refiere a los «abusos del control de constitucionalidad»y, en definitiva, a la crisis del modelo concentrado de justicia constitucional y a su incapacidad para preservar la integridad de la Constitución (debida, entre otros factores, al sistema de elección de magistrados, excesiva tardanza en la resolución, proliferación de las sentencias interpretativas o al creciente volumen de la producción legislativa). La solución que él propone (págs. 213, 221 y ss.) no pasa por la desaparición del Tribunal Constitucional ni por la sustitución del sistema de justicia constitucional concentrada eliminando el recurso y la cuestión de inconstitucionalidad (lo que obligaría a una reforma constitucional profunda e innecesaria), sino por ampliar las facultades de los jueces y tribunales ordinarios a la hora de inaplicar leyes contrarias a la Constitución. No se trataría de atribuirles competencia para declarar la nulidad de las leyes, sino «de dejarlas inaplicadas a los solos efectos de resolver un litigio», habida cuenta de que la técnica de la inaplicación de las normas «forma parte de las facultades reconocidas ordinariamente a los jueces desde el siglo XIX», y de que «también son ellos los que resuelven los problemas de la sucesión de las leyes en el tiempo, deciden sobre la derogación o la retroactividad, que no siempre son operaciones menos delicadas que la simple inaplicación por inconstitucionalidad». Para evitar el problema de seguridad jurídica que se generaría, propone este autor «imponer la obligación, a cualquier juez que inaplica una ley, de plantear inmediatamente después de dictada la sentencia una cuestión de inconstitucionalidad ante el Tribunal Constitucional. La decisión de éste no tendría que afectar a la cosa juzgada, pero sí establecería un criterio definitivo sobre la validez de la ley». 
salvar el fracaso del sistema si en la práctica se hace un uso inadecuado del mismo.

Tercera. La LO 12/2015 recupera el recurso previo de inconstitucionalidad. Lo bace en términos bastante similares al RPI contemplado en la LO 2/1979, aunque reducido, en cuanto a su objeto, a los Estatutos de Autonomía y a las reformas de los mismos. La nueva regulación aporta algunas mejoras, comentadas en los apartados anteriores, como la previsión de que, si el Estatuto o la reforma estatutaria ha de someterse a referéndum éste no podrá ser convocado hasta que el RPI se haya resuelto (y, en su caso, se hayan suprimido o modificado los preceptos declarados inconstitucionales), o el establecimiento de un plazo improrrogable de seis meses desde la interposición del recurso para que éste sea resuelto por el Tribunal. No es posible predecir el resultado práctico de esta reforma ni el balance que, con el transcurso del tiempo, arrojará este reducido y escasamente renovado RPI. Dependerá, entre otros aspectos, de la evolución de nuestro modelo territorial, de las circunstancias que rodeen la actuación del Tribunal, y de que éste, llegado el caso, cumpla el plazo establecido para dictar sus sentencias. Cualquier reflexión de este tipo se encuentra con el problema de que la aplicación práctica puede producir, por motivos de diversa índole, efectos distintos a los previsibles desde una perspectiva teórica. En efecto, no jugamos solo con instituciones o categorías teóricas, sino con instituciones concretas, órganos concretos, compuestos por personas concretas, que juzgan la constitucionalidad de normas concretas en un momento determinado.

Cuarta. Asumido lo anterior, consideramos que, al menos desde una perspectiva técnico-jurídica, el control previo aplicado a determinadas categorías normativas, supondría una mejora en la regulación del sistema español del control de constitucionalidad. Por eso, dando por hecho que cualquier opción a este respecto acarrea sus propios riesgos, habría sido deseable, tal y como hemos indicado en el apartado anterior, su extensión a otras categorías normativas como leyes orgánicas, reglamentos parlamentarios, leyes tributarias y reformas constitucionales aprovechando así las ventajas que ofrece su control con carácter preventivo (y/o eludiendo los inconvenientes que el control a posteriori plantea respecto de estas categorías normativas). Como se apuntó en el apartado I, dichas ventajas pueden resumirse en la seguridad jurídica que aporta el control previo, dado que la norma controlada ya lo ha sido al entrar en vigor, evitándose así la necesidad de reparar los efectos producidos por la norma declarada inconstitucional. A ello se añade la menor lesividad del control al no crear ninguna laguna en el tejido normativo, eliminándose así la problemática relativa a los efectos temporales de la sentencia. Todo ello resulta patente de manera especial en el caso de las leyes orgánicas: al desarrollar éstas materias especialmente sensibles (como los derechos fundamen- 
tales y libertades públicas), puede traer consecuencias irreparables (por irreversibles) su entrada en vigor sin que el Tribunal Constitucional se haya pronunciado sobre su adecuación o no a nuestra Norma Básica. De la STC 66/1985 de 23 de mayo, dictada en relación con la LO 4/1985 que suprimía el recurso previo, se desprende (FJ3) una presunción de constitucionalidad de las leyes, que queda rota cuando se constata que el legislador ha infringido la Constitución. Por tanto, el control de constitucionalidad, bien se ejerza con carácter previo o sucesivo, puede romper esa presunción privando de todo valor a la ley inconstitucional. Puede que el recurso previo no sea «una necesidad del sistema de jurisdicción constitucional», ni tampoco resulte «indispensable para la garantía de la supremacía constitucional» ${ }^{66}$. Sin embargo, su principal aportación consiste en que la presunción se romperá, en su caso, antes de que la norma impugnada entre en vigor, evitando los inconvenientes de la declaración de inconstitucionalidad a posteriori. Por eso, creemos que habría sido deseable una mayor amplitud en cuanto al elenco de normas impugnables vía RPI previsto por la LO 12/2015: una reforma de la LOTC que ni siquiera ha recuperado este recurso en los términos en que se contemplaba hasta su supresión en 1985. Con ello, los detractores del recurso previo se habrán sentido parcialmente aliviados, y sus partidarios solo moderadamente satisfechos.

\section{BIBLIOGRAFÍA}

Alegre Martínez, M. A. (1995): Justicia constitucional y control preventivo, León, Secretariado de Publicaciones de la Universidad de León.

- (2007): «Sobre la conveniencia de recuperar el recurso previo de inconstitucionalidad», en Pablo Pérez Tremps (Coord.), La reforma del Tribunal Constitucional. Actas del V Congreso de la Asociación de Constitucionalistas de España, Valencia, Tirant lo Blanch, 2007, págs. 243-270.

Aragón Reyes, M. (2006): «La construcción del Estado autonómico», en Revista General de Derecho Constitucional, n. ${ }^{\circ}$ 1: Reforma de los Estatutos de Autonomía y Pluralismo Territorial, Madrid, Iustel, págs. 15-38.

Astarloa Huarte-Mendicoa, I. (2014): «Estatutos de Autonomía y Tribunal Constitucional», Diario $A B C, 13$ febrero 2014, pág. 14.

Bilbao Ubillos, J. M. (2006): «El informe del Consejo de Estado sobre la Reforma de la Constitución», Revista General de Derecho Constitucional, n. ${ }^{\circ}$ 1: Reforma de los Estatutos de Autonomía y Pluralismo Territorial, Madrid, Iustel, págs. 153-169.

${ }^{66}$ Cfr. I. Villaverde MenÉndez, «El control previo de constitucionalidad de las normas con rango de ley. Crónica de un escéptico», cit., pág. 30. 
BouzAT, G. (1998): «La argumentación jurídica en el control de constitucionalidad. Una comparación entre la judicial review y el control preventivo y abstracto de constitucionalidad (A propósito de la Sentencia 24-493 de la Corte Suprema Argentina, caso Iachemet, M. ${ }^{a}$ L. vs. Armada Argentina), Revista Española de Derecho Constitucional, n. ${ }^{\circ}$ 54, págs. 273-285.

Brage Camazano, J. (2005): La acción abstracta de inconstitucionalidad, México, Universidad Nacional Autónoma de México, Instituto de Investigaciones Jurídicas (Serie «Doctrina Jurídica», n. $\left.{ }^{\circ} 248\right), 1^{\text {a }}$ edición.

Castellà Andreu, J. M. ${ }^{a}$ (2016): «Tribunal Constitucional y proceso secesionista catalán: respuestas jurídico-constitucionales a un conflicto político-constitucional», Teoría y Realidad Constitucional (UNED), n. ${ }^{\circ} 37$, págs. 561-592.

Cruz Villalón, P. (1981): «El control previo de constitucionalidad», Revista de Derecho Público (2. época), n. ${ }^{\circ} 82$, págs. 5-21.

- (2006): «El control previo, a los veinte años de su supresión», en Juan Luis Requejo Pagés (Coord.): La rebelión de las leyes. Demos y nomos: la agonía de la justicia constitucional, Fundamentos. Cuadernos monográficos de Teoría del Estado, Derecho Público e Historia Constitucional, n. ${ }^{\circ}$ 4/2006, Junta General del Principado de Asturias, págs. 277-290.

De Esteban, J. (2009): «El pronunciamiento catalán», Diario El Mundo, 26 de noviembre de 2009.

FERNÁNDEZ SEGADO, F. (2002): «La obsolescencia de la bipolaridad 'modelo americano/ modelo europeo-kelseniano' como criterio analítico del control de constitucionalidad y la búsqueda de una nueva tipología explicativa», Parlamento y Constitución. Anuario, Cortes de Castilla-La Mancha, Universidad de Castilla-La Mancha, n. ${ }^{\circ}$ 6, págs. 9-73.

GARCía Belaúnde, D. (2006): «Sobre el control de la reforma constitucional (con especial referencia a la experiencia jurídica peruana)», Revista de Derecho Político (UNED), n. ${ }^{\circ}$ 66, págs. 477-500.

García Gestoso, N. (2004): «Algunas consideraciones sobre las reformas de la Constitución española de 1978 derivadas de la integración europea», en Seminario de Profesores de Derecho Constitucional: La reforma constitucional, Universidad de Castilla-La Mancha, 18 de junio 2004, www.uclm.es/actividades0304/seminarios/reforma_constitucional/ponencias/noemi.pdf.

García Roca, J. (2009): Contribuciones en la «Encuesta sobre el Estado autonómiCo» publicada en Teoría y Realidad Constitucional (UNED), n. ${ }^{\circ} 24$, págs. 11-105.

Gerpe LANDín, M. (1983): «El control previo de constitucionalidad», Revista Jurídica de Cataluña, n. ${ }^{\circ} 1$, págs. 197-207.

GiménEZ SÁnCHEZ, I. M. (2007): «Recurso previo de inconstitucionalidad contra proyectos de reforma de Estatutos de Autonomía: viabilidad jurídica de una necesidad política», en Pablo Pérez Tremps (Coord.), La reforma del Tribunal 
Constitucional. Actas del V Congreso de la Asociación de Constitucionalistas de España, Valencia, Tirant lo Blanch, 2007, págs. 355-388.

Gómez Montoro, A. J. (1988): «El control previo de constitucionalidad de proyectos de Estatutos de Autonomía y demás Leyes Orgánicas», Revista Española de Derecho Constitucional, n. ${ }^{\circ}$ 22, págs. 121-174.

GonZÁlez HernándeZ, E. (2016): «El artículo 155 CE y la LO 15/2015, de 17 de octubre, de reforma de la LOTC: ¿Ineludible reciprocidad o círculo perverso?», Teoría y Realidad Constitucional (UNED), n. . 37, págs. 529-557.

GonzÁlez-Trevijano, P. (2004): «Colisión entre constituciones», Diario ABC, 6 de noviembre de 2004.

Groppi, T. (2005): «¿Existe un modelo europeo de Justicia Constitucional?», Revista de Derecho Político (UNED), n. ${ }^{\circ}$ 62, págs. 33-54.

Jimena Quesada, L. (2005): «El lugar de la Constitución en los instrumentos internacionales sobre derechos humanos», en Rumbos del Derecho Internacional de los Derechos Humanos. Estudios en Homenaje al Profesor Antônio Augusto Cançado Trindade, tomo V, Brasil, Porto Alegre, Sergio Antonio Fabris Editor, págs. 195-256.

- (2007): «La inconstitucionalidad del control de constitucionalidad sucesivo de los tratados internacionales (crítica a la postura mantenida por el Tribunal Constitucional español)», en Pablo Pérez Tremps (Coord.), La reforma del Tribunal Constitucional. Actas del V Congreso de la Asociación de Constitucionalistas de España, Valencia, Tirant lo Blanch, 2007, págs. 419-439.

MuÑoz Machado, S. (2006): El problema de la vertebración del Estado en España (Del siglo XVIII al siglo XXI), Madrid, Iustel, 2006.

- (2012): Informe sobre España, Barcelona, Editorial Crítica.

Pegoraro, L. (2002): «La circulación, la recepción y la hibridación de los modelos de Justicia constitucional», Anuario Iberoamericano de Justicia Constitucional, n. ${ }^{\circ}$ 6, 2002, págs. 393-416. Traducción de Francisco Fernández Segado, a partir de un texto inicial de Rafael Rubio Núñez, revisado y modificado.

- (2006): «Clasificaciones y modelos de justicia constitucional en la dinámica de los ordenamientos», en Javier Pérez Royo, Joaquín Pablo Urías Martínez y Manuel Carrasco Durán (Eds.), Derecho Constitucional para el Siglo XXI, Actas del VIII Congreso Iberoamericano de Derecho Constitucional, Navarra, Thomson/ Aranzadi, tomo II, págs. 4201-4225.

Pérez Royo, J. (1986): «Crónica de un error: el recurso previo de inconstitucionalidad contra leyes orgánicas», Revista Española de Derecho Constitucional, n. ${ }^{\circ} 17$, págs. 137-170. 
Presno Linera, M. A. (2014): «El regreso del recurso previo de inconstitucionalidad», en el Blog El derecho y el revés, 29 enero 2014: https://presnolinera.wordpress.com/2014/01/29/el-regreso-del-recurso-previo-de-inconstitucionalidad/

Rodríguez GaONA, R. (2006): El control constitucional de la reforma a la Constitución, Madrid, Dykinson.

Rubio Llorente, F. (2012): «La jurisdicción constitucional en España», y «Tendencias actuales de la jurisdicción constitucional en Europa», ambos en La forma del poder. Estudios sobre la Constitución, Madrid, Centro de Estudios Políticos y Constitucionales, 3. a ed., 2012, vol. III, págs. 1209-1249 y $1373-1394$.

Salazar Benítez, O. (2007): «Sobre la inconveniencia de introducir el recurso previo de inconstitucionalidad en los procedimientos de reforma estatutaria», en Pablo Pérez Tremps (Coord.), La reforma del Tribunal Constitucional. Actas del $V$ Congreso de la Asociación de Constitucionalistas de España, Valencia, Tirant lo Blanch, 2007, págs. 459-485.

SÁnchez De Vega García, A. (1991): «Acerca del recurso previo de inconstitucionalidad», Revista de las Cortes Generales, n. ${ }^{\circ} 23$, págs. 53-77.

Santaolalla López, F. (1983): «Problemas del recurso previo de inconstitucionalidad y adición sobre la LOAPA», Revista de Derecho Político (UNED), n. ' 18-19, págs. 177-190.

Tajadura Tejada, J. (2007): «Reformas estatutarias y control previo de constitucionalidad», en Pablo Pérez Tremps (Coord.), La reforma del Tribunal Constitucional. Actas del V Congreso de la Asociación de Constitucionalistas de España, Valencia, Tirant lo Blanch, 2007, págs. 487-503.

Torres Del Moral, A. (2004): Principios de Derecho Constitucional Español. Tomo II: Instituciones Políticas, Madrid, Servicio de Publicaciones de la Facultad de Derecho de la Universidad Complutense, 5. a edición.

- (2010): Principios de Derecho Constitucional español. Tomo I: Sistemas de fuentes. Sistema de los derechos, Madrid, Servicio de Publicaciones de la Facultad de Derecho de la Universidad Complutense, 6. ${ }^{\text {a }}$ edición.

Villaverde Menéndez, I. (2014): «El control previo de constitucionalidad de las normas con rango de ley. Crónica de un escéptico», Revista Catalana de Dret Public, n. ${ }^{4}$ 9, págs. 20-40. DOI: 10.2436/20.8030.01.30.

Title:

Prior appeal of unconstitutionality according to the Organic Law 12/2015: an expected return, an insufficient amendment. 


\section{Summary:}

Introduction. I. Prior appeal of unconstitutionality until its suppression in 1985. II. The debate about the need of its recovery. III. Inmediate antecedents: the propositions of Organic Law of January 24, 2014. IV. The Organic Law 12/2015: Procedure, justification and content. V. The Organic Law 12/2015: Analysis, valuation and proposals. Conclusions. Bibliography.

\section{Resumen:}

Este trabajo gira en torno a la Ley Orgánica 12/2015 de 22 de septiembre, que recupera la figura del recurso previo de inconstitucionalidad para los Estatutos de Autonomía y sus reformas. Dicha Ley encuentra sus antecedentes más cercanos en las dos iniciativas parlamentarias presentadas en 2014 por los grupos popular y socialista (que finalmente pactarían su contenido) y su precedente más remoto en la anterior regulación del recurso previo por la Ley Orgánica 2/1979 de 3 de octubre, con la que también guarda gran similitud, fundamentalmente en cuanto a legitimación, momento de interponer el recurso, o tramitación del mismo. La comparación entre estas cuatro versiones del recurso previo se lleva a cabo primeramente desde una óptica más descriptiva, dejando paso después a un enfoque más crítico sobre el contenido de la LO 12/2015 y algunos de los problemas que plantea, tanto por el contenido de la reforma que reintroduce el recurso previo (legitimación, plazo para dictar sentencia, coexistencia con el control sucesivo), como por todo lo que en ella se echa de menos (extensión del recurso previo a las leyes orgánicas y otras normas).

Las reformas estatutarias emprendidas en España a partir de 2006 reabrieron el debate sobre el recurso previo (que hasta su supresión en 1985 era posible para los Estatutos de Autonomía y las demás Leyes Orgánicas) y la necesidad de su recuperación. La LO 12/2015 cubre solo parcialmente las expectativas, puesto que introduce un recurso previo reducido y escasamente renovado, limitando su objeto a los Estatutos de Autonomía y sus reformas, y no extendiéndolo a las demás leyes orgánicas, las reformas constitucionales y otras normas, respecto de las cuales presentaría importantes ventajas frente al control sucesivo.

Cualquier solución que se adopte para controlar la constitucionalidad de las leyes es mejorable. Una de las vías para fortalecer el modelo español sería la previsión de un control de constitucionalidad previo y obligatorio para determinados tipos normativos. En este sentido, se 
plantean en el artículo propuestas que podrían servir para mantener abierto el debate de cara a eventuales reformas futuras.

\section{Abstract:}

This paper analyzes the Organic Law 12/2015 of 22 September, that recovers the figure of prior appeal of unconstitutionality with regard to Statutes of Autonomy and its amendments. Such law finds its immediate antecedents in two parliamentary initiatives presented in 2014 by them Popular and Socialist groups (that finally agreed to its content) and its preceding more remote in the previous regulation of prior appeal by the Organic Law 2/1979 of 3 October, with which also keeps great similarity, fundamentally with regard to legitimation, time of interposing the resource, or its procedure. The comparison among these four versions of the previous resource is first conducted from a perspective more descriptive, then giving way to an approach more critical about the content of the Organic Law 12/2015, and some of raised problems, both by the content of the reform which re-introduces the previous resource (legitimation, deadline for ruling, coexistence with the successive control), as by all what in it is check of less (extension of the previous resource to organic laws and another rules).

The amendments of statutes of autonomy undertaken in Spain since 2006, reopened the debate on prior appeal of unconstitutionality (which, until its suppression in 1985 was possible for them statutes of autonomy and them other organic laws) and the need of its recovery. The Organic Law 12/2015 covers only partially the expectative, because it introduces a reduced and shortly renovated prior appeal, limiting its object to the statutes of autonomy and its amendments, and not extending it to other organic laws, constitutional reforms and other rules, which would provide significant advantages in comparison with successive control.

Any solution adopted for controlling the constitutionality of laws is improvable. One of the ways to strengthen the Spanish model would be the introduction of a previous, preceptive and obligatory control of constitutionality for certain normative rules. In this sense, the article raises proposals that could be used to keep open the debate, face to any future reforms.

\section{Palabras clave:}

Tribunal Constitucional, control de constitucionalidad, estatutos de autonomía, recurso previo de inconstitucionalidad: antecedentes, debate, regulación, propuestas. 
Key words:

Constitutional Court, control of constitutionality, statutes of autonomy, prior appeal of unconstitutionality: antecedents, debate, regulation, proposals. 